Delft University of Technology

\title{
Foam Generation and Rheology in a Variety of Model Fractures
}

Alquaimi, Bander; Rossen, Bill

DOI

10.1021/acs.energyfuels.8b02178

Publication date

2019

Document Version

Final published version

Published in

Energy \& Fuels

\section{Citation (APA)}

Alquaimi, B., \& Rossen, B. (2019). Foam Generation and Rheology in a Variety of Model Fractures. Energy \& Fuels, 33(1), 68-80. https://doi.org/10.1021/acs.energyfuels.8b02178

\section{Important note}

To cite this publication, please use the final published version (if applicable).

Please check the document version above.

Other than for strictly personal use, it is not permitted to download, forward or distribute the text or part of it, without the consent of the author(s) and/or copyright holder(s), unless the work is under an open content license such as Creative Commons.

\section{Takedown policy}

Please contact us and provide details if you believe this document breaches copyrights.

We will remove access to the work immediately and investigate your claim. 
Green Open Access added to TU Delft Institutional Repository

'You share, we take care!' - Taverne project

https://www.openaccess.nl/en/you-share-we-take-care

Otherwise as indicated in the copyright section: the publisher is the copyright holder of this work and the author uses the Dutch legislation to make this work public. 


\title{
Foam Generation and Rheology in a Variety of Model Fractures
}

\author{
B. I. AlQuaimi ${ }^{*} \dagger,+\infty$ and W. R. Rossen ${ }^{\dagger}$ \\ ${ }^{\dagger}$ Department of Geoscience and Engineering, Delft University of Technology, Delft, 2628 CD, Netherlands \\ ${ }^{\ddagger}$ Saudi Aramco, Saudi Arabian Oil Co., Southern Area Reservoir Management, Dhahran, Eastern Province, 31311, Saudi Arabia
}

Supporting Information

ABSTRACT: Gas is used in petroleum reservoirs to displace oil for enhanced oil recovery. The microscopic displacement efficiency of gas is very good, but at the reservoir scale the process suffers from poor sweep efficiency, especially in naturally fractured reservoirs. Foam can improve the sweep. There have been considerable scientific contributions toward understanding foam flow in nonfractured porous media, with relatively little work on foam flow in fractured porous media. We investigate foam-generation mechanisms in five fully characterized glass models of fractures with different apertures and correlation lengths of the aperture distribution. We also study the rheology of the in situ-generated foam by varying the superficial velocities of the gas and surfactant solution. We compare the measured pressure gradient against the fracture attributes, aperture, and the correlation length of the aperture. We also compare foam texture as a function of position within the fracture as the generated foam propagates through the fracture. Gas mobility was greatly reduced as a result of in situ foam generation in our model fractures. Foam was generated predominantly by capillary snap-off and lamella division. The measured mobility reduction depends on fracture attributes. Fracture-wall roughness, represented by both the hydraulic aperture and the correlation length of the aperture, plays an important role in foam generation and mobility. The average bubble size increases as the aperture increases, which results in a significant decrease in pressure gradient. Two model fractures show the same two foam-flow regimes central to the understanding of foam in nonfractured porous media: a low-quality regime where pressure gradient is independent of liquid velocity and a high-quality regime where pressure gradient is independent of gas velocity. The mechanisms thought to be behind these two regimes in nonfractured porous media do not apply to these experiments, however.

\section{INTRODUCTION}

Foam is injected to recover the undisplaced oil in petroleum reservoirs. Foam has been applied in the field from as early as the 1960s. ${ }^{1}$ A foam pilot test was conducted in the Snorre Field, starting with laboratory experiments and numerical simulations. ${ }^{2-4}$ Experience and the benefits of steam-foam injection in many field applications are reported in the literature. ${ }^{5}$ Foam is also used in acid diversion for selective stimulation. ${ }^{6,7}$ Foam was also used for the remediation of an aquifer. ${ }^{8}$

Many petroleum reservoirs have natural fractures caused by earth stresses. ${ }^{9}$ Natural fractures vary in aperture, length, orientation, asperities, and wall roughness. ${ }^{10-12}$ Studies have examined foam flow in fractures in the last two decades. Pregenerated foam was injected into sawed rock core samples or blocks to study oil recovery. ${ }^{13-15}$ Pregenerated foam was injected in parallel slits to study sweep and foam rheology. ${ }^{16}$ Studies of pregenerated foam in microfluidic devices as an approximation to fracture flow have been also reported. ${ }^{17,18}$ The investigation of foam flow in fracture replicas with apertures of roughly 30 and $100 \mu \mathrm{m}$ have been reported. ${ }^{19}$ Foam generation and sweep efficiency in a fractured rock slab with an aperture of approximately $100-150 \mu \mathrm{m}$ was also investigated. ${ }^{20}$ These studies report the pressure gradient across the entire sample, so it is not possible to know how foam texture or pressure evolves as foam propagates through the sample. Moreover, most studies involved the injection of pregenerated foam. In-situ foam generation and propagation in a physical-model fracture along with foam texture and pressure gradient versus distance from the injection face was reported in one study. ${ }^{21}$
Fractures can vary in aperture and in the roughness of the fracture wall. It is important to examine how the geometry of the fracture porespace affects foam generation, propagation, and mobility. This paper shows the results of in situ foam generation in five distinct model fractures. The fractures vary in aperture and correlation length of the aperture. The study also addresses foam texture as a function of roughness scale and aperture variation. In addition, it shows the effect of fracture aperture on foam texture and pressure gradient. It is an initial step toward understanding how fracture geometry affects foam properties, which would extend current studies of foam in individual fractures and allow prediction of foam behavior under moregeneral circumstances.

\section{MATERIALS AND METHODS}

Experimental Apparatus and Method. Figure 6 shows the experimental apparatus, the same as that used in a previous study. ${ }^{21}$ Sodium C14-16 alpha olefin sulfonate (Bio-Terge-AS-40 KSB, Stepan, Voreppe, France), an anionic surfactant with $39 \mathrm{wt} \%$ active component and a critical micelle concentration of $301.0 \mathrm{mg} / \mathrm{L}$, was used in the study. All experiments employed a $1.0 \mathrm{wt} \%$ surfactant solution in demineralized water. The surfactant solution was injected using a Standard Infusion PHD Ultra syringe pump (model-703005, Harvard Apparatus, Holliston, MA, USA). Flow rates are stated to be accurate to within $0.25 \%$, with reproducibility within $0.05 \%$ of full scale. This pump is equipped with microstepping techniques to further reduce flow pulsation. The pump has a range from $0.0001 \mu \mathrm{L} / \mathrm{h}$ to $216 \mathrm{~mL} / \mathrm{min}$.

Received: August 22, 2018

Revised: November 25, 2018

Published: November 28, 2018 


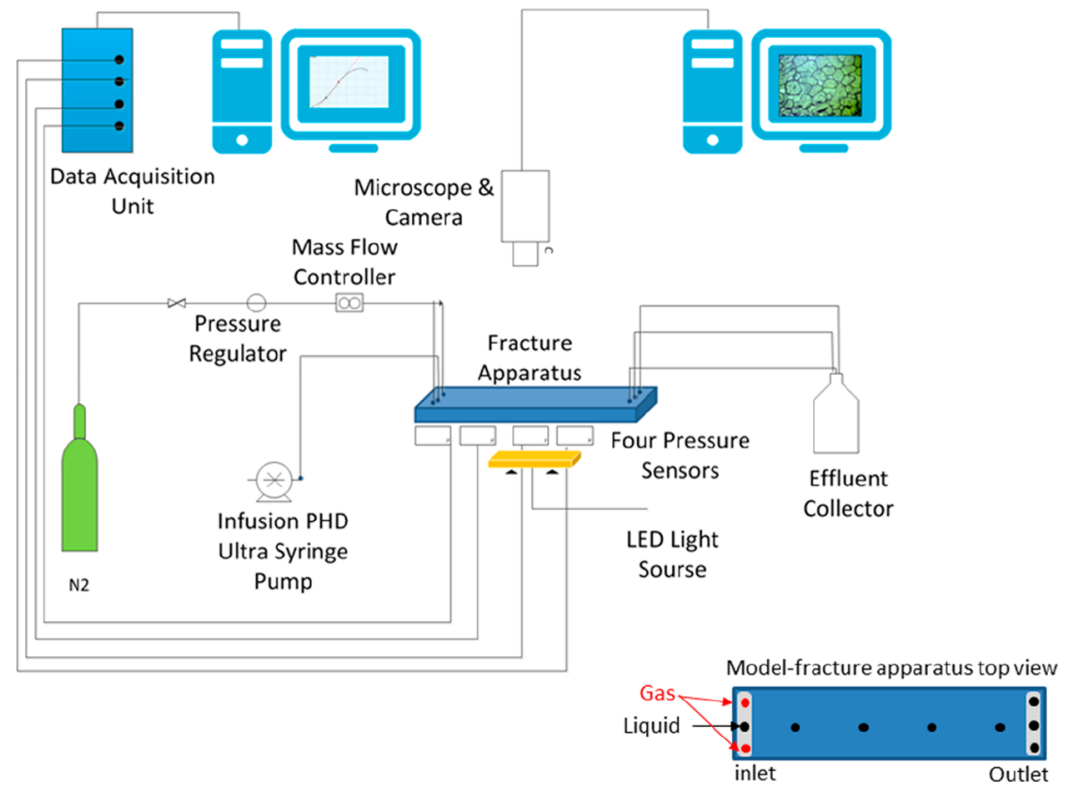

Figure 1. Schematic of the experimental setup. The injection and production lines are fitted from the bottom of the fracture plate, but are drawn from the top here to avoid clutter in the diagram. The bottom right shows the model-fracture layout with injection and pressure ports.

Nitrogen was injected through a gas mass-flow meter/mass-flow controller (EL-Flow F-230M-RAD-22-K, Bronkhorst High-Tech B.V., Ruurlo, Netherlands) which has a range of $0-10 \mathrm{mln} / \mathrm{min}$. The bottom (roughened) glass plate includes four pressure ports, with a distance of $9.0 \mathrm{~cm}$ between them, to provide pressure readings across the length of the apparatus. The pressure-difference sensors are signal-conditioned and temperature-compensated. Three different ranges of sensors are used depending on pressure. The sensors (MPXV5004DP, MPXV5010DP, and MPXV5050DP, Freescale Semiconductor, Inc., Austin, TX, USA), with ranges of 0 to 4,0 to 10 , and 0 to $50 \mathrm{kPa}$, respectively, have a maximum error of $5.0 \%$ from 0 to $85{ }^{\circ} \mathrm{C}$ temperature. The sensors were connected to a data-acquisition unit and a computer, where pressure is recorded every second.

For monitoring in situ foam generation and foam texture we used a LEICA MZ 8 microscope (10445538 1.0X, Leica Microsystems B.V., Amsterdam, Netherlands). The microscope is connected to DRS's lightning RDTTM camera, consisting of a small camera head, detachable cable, and custom frame-grabber board. The lightning RDTTM is an ultrafast, high-resolution camera that captures $1280 \times$ 1024 resolution images at 500 full frames per second (fps). A higher fps of 16000 can be achieved at reduced resolution for recording extremely rapid events. MiDAS 2.0 camera-control software (Xcitex Inc., Woburn, MA, USA) was used to process the images/videos in real time during recording. A compact backlight (model CVI STAR-BL-110/110-WH24 V; Stemmer Imaging B.V.) provided constant and even illumination. Uniform light is needed to produce noise-free images.

Three sets of experiments were carried out using this setup, after measuring experimentally the hydraulic aperture of each fracture:

1 In-situ foam generation: The fracture was first vacuum-saturated with water (no surfactant), followed by coinjection of gas and surfactant solution. The foam-generation mechanisms within each of the fractures were observed and categorized.

2 Foam propagation: Once the foam had been generated, its behavior and evolution as it propagated through the model was investigated.

3 Foam-quality scan: After foam flow had been established throughout the fracture, the pressure gradient across the four sections was recorded until a stable signal was observed. The variation in the pressure gradient with foam quality, holding total superficial velocity $u_{t}$ constant, could then be recorded.

Model Fractures. Model fractures made of glass plates have previously been used to study foam and two-phase flow in fractures. ${ }^{16,21-29,45}$ Glass-model fractures provide the ability to observe the flow and investigate the mechanisms of foam generation. More importantly, they allow one to systematically vary roughness scales (magnitude of aperture, aperture variation, and the length scale over which the aperture varies) and investigate the effect of these on foam generation, stability, and mobility. Our goal is to cover a wide range of apertures and different fracture geometries encountered in fractured reservoirs. Figures 2 to 6 show the fracture-wall surface topography of our model fractures.

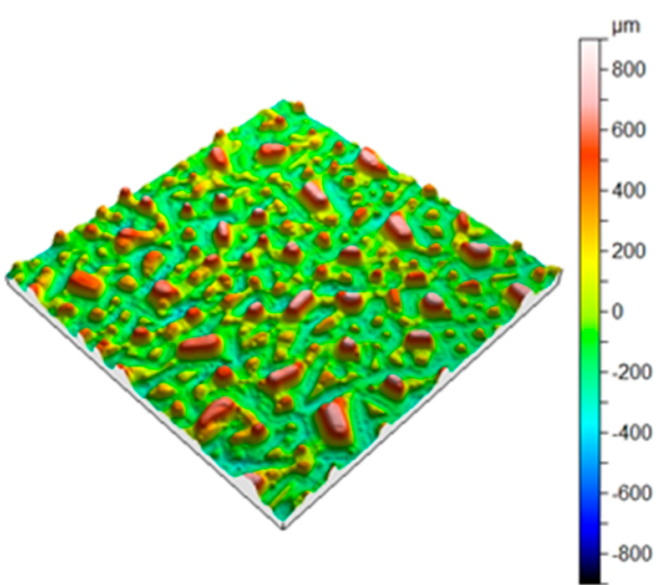

Figure 2. Sample 1:3D surface topography. The patch shown is $4 \times 4$ $\mathrm{cm}^{2}$.

The model fractures used here consist of a roughened plate to represent the fracture roughness and a top plate that is smooth, to allow direct observation of the flow. One model fracture (Sample 2) has a 40 $\times 10 \mathrm{~cm}$ plate with regular patterns in its roughness. The remaining four model fractures have $43 \times 10 \mathrm{~cm}$ plates with significant differences between them in their roughness scales. The roughened plate is $4 \mathrm{~mm}$ thick and was strengthened by attaching a $15 \mathrm{~mm}$-thick plate of glass to the back using DELO Photobond glue (DELO, Windach, Germany). The thickness of the top glass plate was also $15 \mathrm{~mm}$. The required thickness of the glass plates was estimated using solid-mechanics calculations to prevent any glass deflection during the flow. The glass deflection was also checked using a probe indicator $(2 \mu \mathrm{m}$ resolution $)$ during the experiment. 


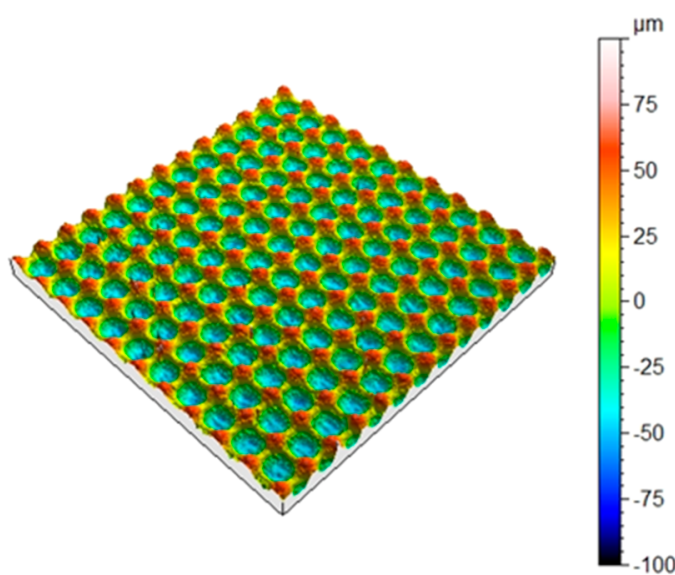

Figure 3. Sample 2:3D surface topography. The patch shown is $1 \times 1$ $\mathrm{cm}^{2}$.

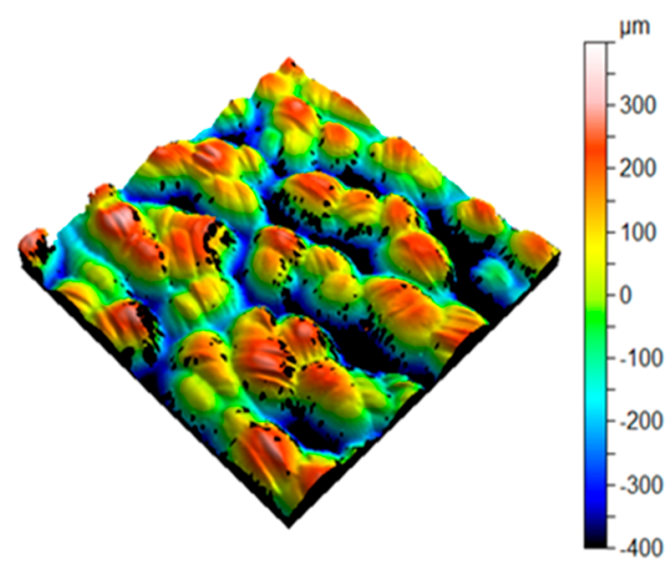

Figure 4. Sample 3:3D surface topography. The patch shown is $4 \times 4$ $\mathrm{cm}^{2}$.

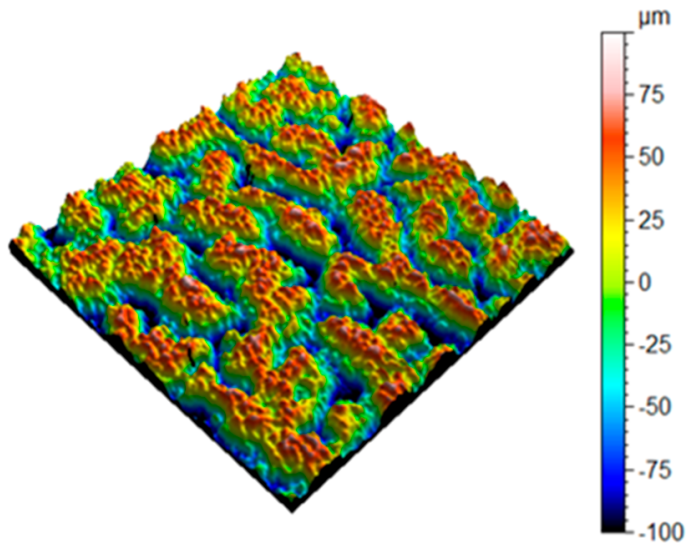

Figure 5. Sample 4:3D surface topography. The patch shown is $4 \times 4$ $\mathrm{cm}^{2}$.

In all the model fractures the roughened glass plates include three inlet ports that allow a separate coinjection of gas and liquid. These inlet ports are equally spaced and connected to an $8.0 \times 2.0 \times 0.04 \mathrm{~cm}$ entry trough milled into the roughened plate (Figure 6, bottom right). The middle inlet port was used for liquid injection and the other two inlet ports for gas injection. Sample 2 has a single port for outflow without a milled outlet trough. ${ }^{29}$ The milled outlet trough in the other four samples eliminates radial converging flow to the single outlet port that we observed in Sample 2. For Samples 1, 3, 4, and 5, the roughened glass plates include four pressure ports spaced over a length of $39 \mathrm{~cm}$ and an

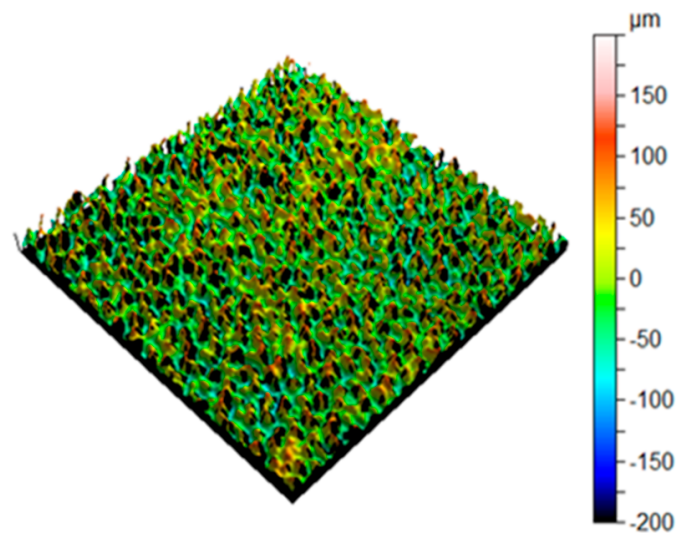

Figure 6. Sample 5:3D surface topography. The patch shown is $4 \times 4$ $\mathrm{cm}^{2}$.

$8.0 \times 2.0 \times 0.04 \mathrm{~cm}$ milled outlet region. The fourth pressure port is located $2 \mathrm{~cm}$ upstream of the outlet trough. Thus, behavior in the fourth section, between taps 3 and 4 , is thus relatively isolated from the capillary end effect at the edge of the fracture.

The gap between the top plate and the rough surface represents the fracture aperture. The two glass plates are glued together at the edges using Araldite 2014, an epoxy adhesive that has a tensile strength of 26 MPa at $23^{\circ} \mathrm{C}$. The fracture is mounted in a frame that can slide $50 \mathrm{~cm}$ in the $X$ and $Y$ directions to allow for microscopic observation of the flow in the whole $43 \times 10 \mathrm{~cm}$ fracture.

A fracture can be considered a two-dimensional network of pore bodies (maxima in aperture) connected by throats (saddle points between pore bodies). ${ }^{30-33}$ To characterize the two-dimensional network, a $4 \times 4 \mathrm{~cm}^{2}$ patch of each roughened glass sample was profiled to quantify the spatial and vertical variations in height. Images and statistics of the pore throats and pore bodies were reported previuosly. ${ }^{34}$ We identify the characteristic pore-throat aperture $\left(d_{t}\right)$ as that at the percolation threshold, a characteristic pore-body aperture $\left(d_{\mathrm{b}}\right)$ that is the average pore-body aperture, and a characteristic pore length $\left(L_{\mathrm{p}}\right)$ that is the average pore-body length of the $2 \mathrm{D}$ network in the flow direction. A separate measure would be the correlation length of aperture. Table 1 shows that these two measures correlate well with each other. The hydraulic aperture $d_{\mathrm{h}}$ was measured experimentally by injecting water and obtaining the relationship between flow rate and pressure drop. ${ }^{35}$ We estimated pore-throat width $w_{\mathrm{t}}$ (Table 1) by estimating the average pore throat on the percolation path and determining the width of that throat at that aperture. Table 1 summarizes the fracture-aperture data for all five fractures. The modelfracture topography in each case, with the conceptual 2D network superimposed on the images, is given in Appendix A in the Supporting Information.

Samples $4 a, 4 b, 5 a$, and $5 b$ were fabricated to investigate the effect of the hydraulic aperture $\left(d_{\mathrm{h}}\right)$ at a fixed $L_{\mathrm{p}}$. The model fractures were fabricated from glass plates similar to samples 4 and 5 , but with spacers with known thickness (and dimensions $0.5 \times 0.5 \mathrm{~cm}^{2}$ ) distributed uniformly, mainly at the fracture perimeter. Additionally, four spacers, one in the center of each section, were placed to prevent deformation of the sample. The spacers occupy only $0.01 \%$ of the total area available for flow. We measured the hydraulic aperture for each model after fabrication.

\section{RESULTS}

In-Situ Foam Generation. We observed foam generation in our five model fractures, with corresponding mobility reduction of the gas. Foam was generated in situ mainly by snap-off and lamella division. In samples 2, 3, and 4, both lamella division and repeated snap-off occurred. The throats in these samples are wide in the plane of the fracture (Appendix A) but narrow in 
Table 1. Model Fracture Aperture and Roughness Data (All Measurements Are in $\mu \mathrm{m}$ )

\begin{tabular}{|c|c|c|c|c|c|c|}
\hline $\begin{array}{l}\text { sample } \\
\text { no. }\end{array}$ & $\begin{array}{l}\text { hydraulic aperture (experimentally } \\
\text { determined), } d_{\mathrm{h}}\end{array}$ & $\begin{array}{l}\text { pore-throat aperture, } \\
d_{\mathrm{t}}\end{array}$ & $\begin{array}{l}\text { pore-body aperture, } \\
\qquad d_{\mathrm{b}}\end{array}$ & $\begin{array}{l}\text { pore length, } \\
l_{\mathrm{p}}\end{array}$ & $\begin{array}{l}\text { correlation length, } \\
l_{\text {cor }}\end{array}$ & $\begin{array}{l}\text { pore-throat width, } \\
\qquad w_{\mathrm{t}}\end{array}$ \\
\hline 1 & 670 & 818 & 1128 & 2661 & 2754 & 1550 \\
\hline 2 & 66 & 68 & 138 & 819 & 795 & 410 \\
\hline 3 & 330 & 443 & 853 & 5156 & 4800 & 1650 \\
\hline 4 & 51 & 100 & 210 & 4415 & 5100 & 1130 \\
\hline $4 a$ & 72 & 121 & 231 & 4415 & 5100 & 1130 \\
\hline $4 b$ & 204 & 253 & 363 & 4415 & 5100 & 1130 \\
\hline 5 & 115 & 131 & 211 & 2421 & 2240 & 460 \\
\hline $5 a$ & 145 & 161 & 241 & 2421 & 2240 & 630 \\
\hline $5 b$ & 170 & 186 & 265 & 2421 & 2240 & 630 \\
\hline
\end{tabular}

aperture $d_{\mathrm{t}}$ (Table 1 ); this slit-shaped geometry favors snapoff $^{36,37,45}$ (Appendix B in the Supporting Information).

In sample 2 snap-off created bubbles that are much smaller than the pores. ${ }^{21}$ Lamella division was observed at high gas fractional flow $\left(f_{\mathrm{g}}\right)$. Figure 7 shows snap-off events in sample 2 at

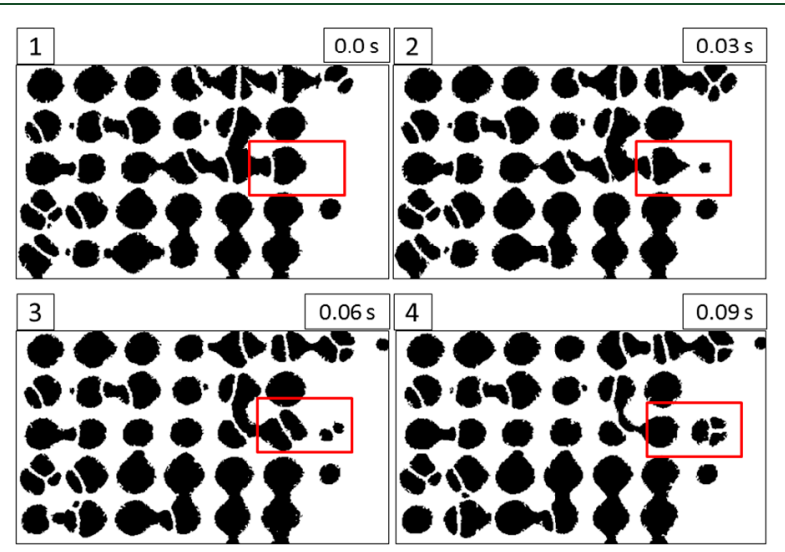

Figure 7. Sample 2: foam generation by snap-off; image size $(0.75 \times$ $\left.0.43 \mathrm{~cm}^{2}\right) \cdot f_{\mathrm{g}}=0.37$ and $u_{\mathrm{t}}=0.0021 \mathrm{~m} / \mathrm{s}$. Black is gas and white is water. Area of interest is highlighted in red.

$f_{\mathrm{g}}=0.37$ and a total superficial velocity $\left(u_{\mathrm{t}}\right)$ of $0.0021 \mathrm{~m} / \mathrm{s}$; in all images the flow is from left to right. Figure 8 shows lamella division at $f_{\mathrm{g}}=0.87$ and $u_{\mathrm{t}}=0.0049 \mathrm{~m} / \mathrm{s}$. In these and similar images to follow, the white area represents water, which occupies the peaks in the topography of Figures 1-5 (i.e., locations of narrowest aperture) and some pore throats (saddle

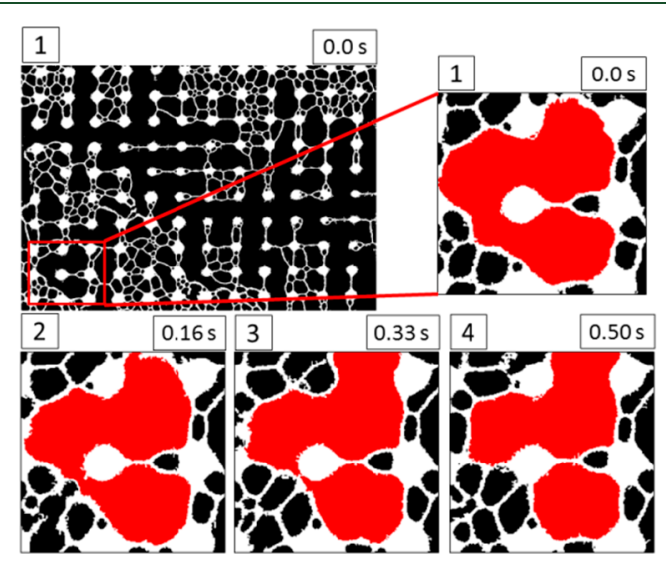

Figure 8. Sample 2: foam generation by lamella division; image size $\left(0.21 \times 0.2 \mathrm{~cm}^{2}\right) \cdot f_{\mathrm{g}}=0.87$ and $u_{\mathrm{t}}=0.0049 \mathrm{~m} / \mathrm{s}$. Black is gas and white is water. The divided bubble is highlighted in red. points between peaks; see Appendix A). Gas occupies the pore bodies (i.e., locations of widest aperture, or valleys in Figures 1-5). Lamellae appear as white lines in Figure 7 and following. We observe foam generation by lamella division when a lamella leading a large bubble divides as it encounters a split in the flow path. We did not observe lamella division at $f_{\mathrm{g}}$ lower than 0.76 in sample 2, probably because bubbles were too small to divide.

In $3 \mathrm{D}$ pore networks, interbubble diffusion can rapidly eliminate bubbles much smaller than pores. In our experiments, diffusion does not have time to eliminate these bubbles because bubble residence time in our model is relatively short, approximately $2.7 \mathrm{~min}^{21}$ A similar observation of bubbles smaller than pores was reported in another study of foam flow in fractures. $^{20}$

In samples 3 and 4 we also observed snap-off; see Figures 9 and 11, respectively. Samples 3 and 4 differ greatly in their
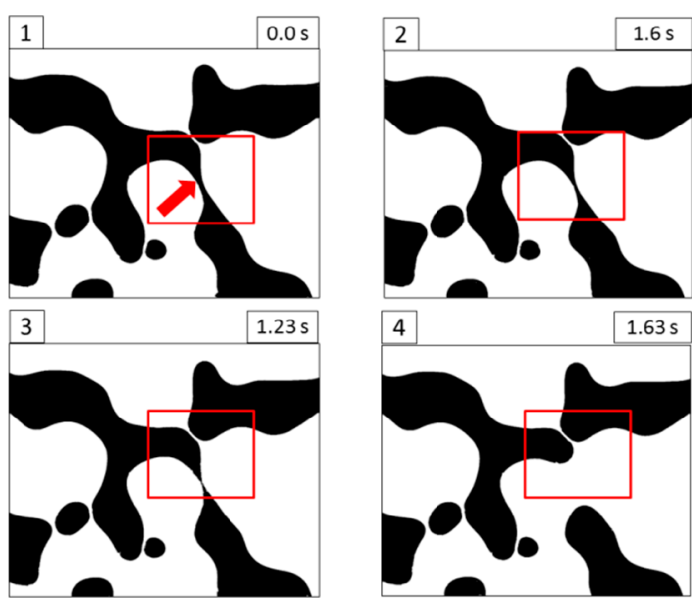

Figure 9. Sample 3: foam generation by snap-off (see arrow and box); image size $\left(2.6 \times 2.1 \mathrm{~cm}^{2}\right) \cdot f_{\mathrm{g}}=0.45$ and $u_{\mathrm{t}}=0.0013 \mathrm{~m} / \mathrm{s}$. Black is gas and white is water.

hydraulic apertures and correlation length for aperture (Table 1 ). This led to significant differences in foam texture (cf. Figures 9 and 11), foam texture as a function of position (discussed in the next section), and pressure response. Moreover, in samples 3 and 4 lamella division occurred at flow conditions that were similar to those of snap-off in the same samples. Figures 10 and 12 show lamella division in Samples 3 and 4, respectively.

In samples 1 and 5, foam was generated primarily by lamella division (cf. Figures 13 and 14). In sample 1 the throats are deeper than in the other samples, and thus less slit-like. In sample 5 the throats are slightly deeper than in sample 4, for instance, but not nearly as wide in the plane of the fracture 


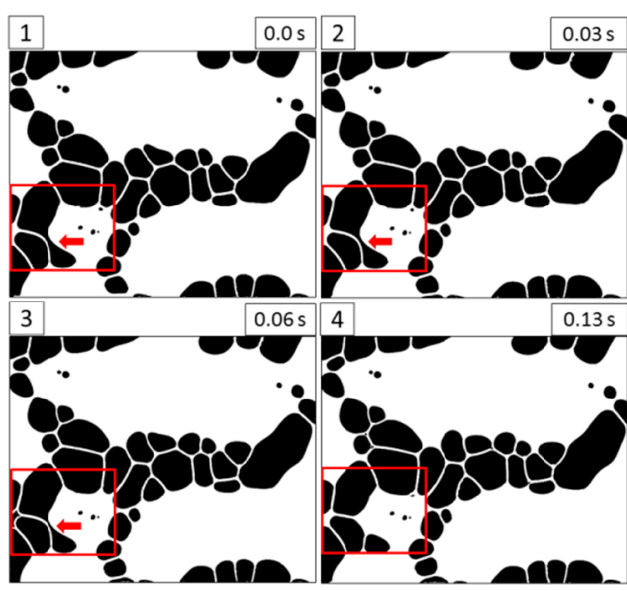

Figure 10. Sample 3: foam generation by lamella division (see arrow and box); image size $\left(2.6 \times 2.1 \mathrm{~cm}^{2}\right) \cdot f_{\mathrm{g}}=0.45$ and $u_{\mathrm{t}}=0.0025 \mathrm{~m} / \mathrm{s}$. Black is gas and white is water.

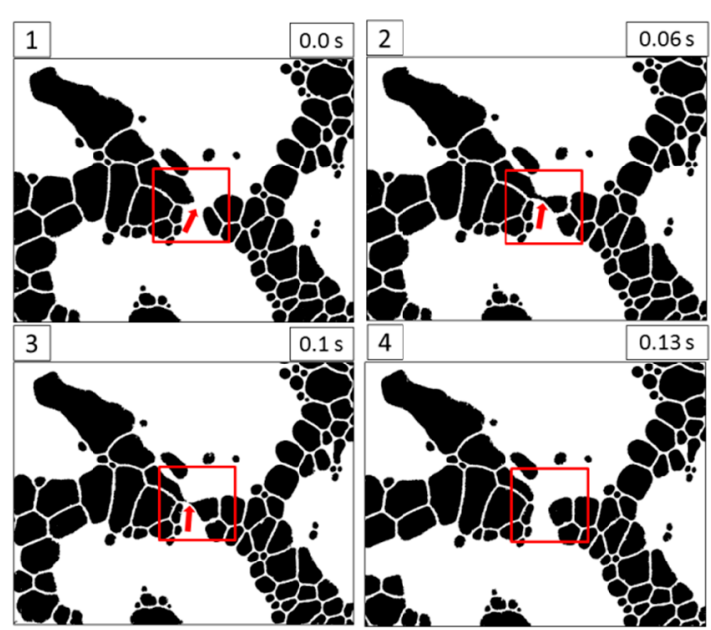

Figure 11. Sample 4: foam generation by snap-off (see arrow and box); image size $\left(1.1 \times 0.9 \mathrm{~cm}^{2}\right) \cdot f_{\mathrm{g}}=0.68$ and $u_{\mathrm{t}}=0.0032 \mathrm{~m} / \mathrm{s}$. Black is gas and white is water.
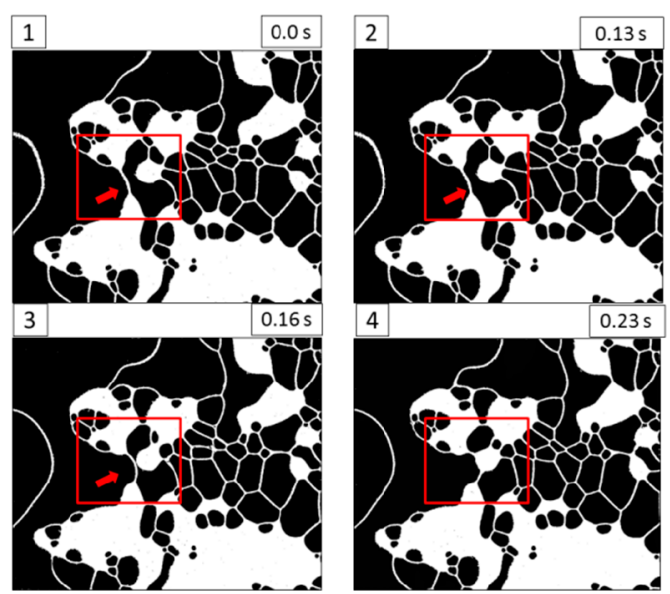

Figure 12. Sample 4: foam generation by lamella division (see arrow and box $)$; image size $\left(0.72 \times 0.66 \mathrm{~cm}^{2}\right) \cdot f_{\mathrm{g}}=0.45$ and $u_{\mathrm{t}}=0.0016 \mathrm{~m} / \mathrm{s}$. Black is gas and white is water.

(Figures 4 and 5, Appendix A): again, less slit-like and less favorable to snap-off. The large aperture of sample 1 has a significant impact on foam texture and pressure gradient, as

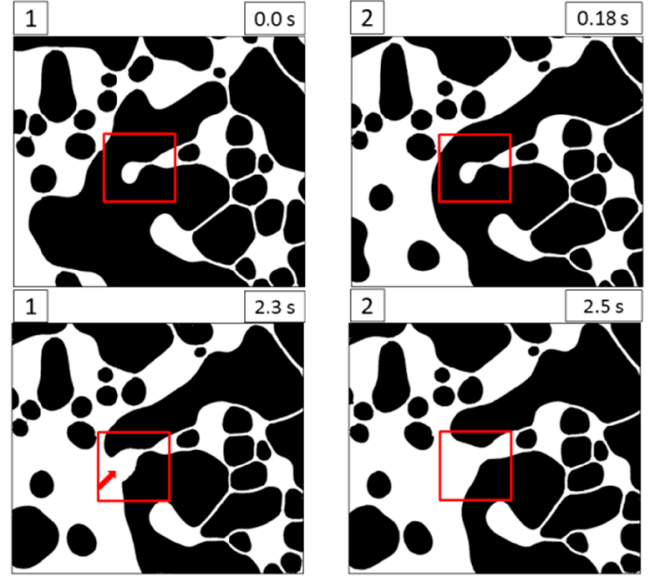

Figure 13. Sample 1: foam generation by lamella division (see arrow and box $)$; image size $\left(2.1 \times 1.8 \mathrm{~cm}^{2}\right) \cdot f_{\mathrm{g}}=0.60$ and $u_{\mathrm{t}}=0.0025 \mathrm{~m} / \mathrm{s}$. Black is gas and white is water.

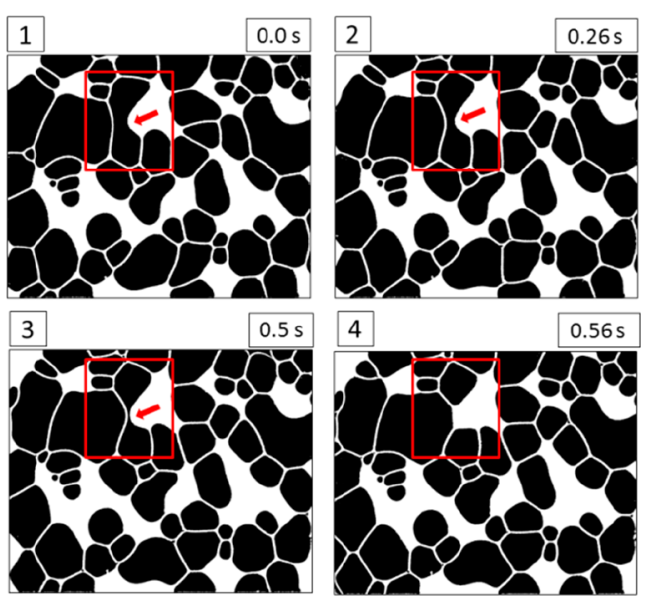

Figure 14. Sample 5: foam generation by lamella division (see arrow and box $)$; image size $\left(1.2 \times 0.96 \mathrm{~cm}^{2}\right) \cdot f_{\mathrm{g}}=0.70$ and $u_{\mathrm{t}}=0.0007 \mathrm{~m} / \mathrm{s}$. Black is gas and white is water.

discussed below. These results show that the foam-generation mechanism is a function of aperture, fracture-wall geometry, gas fractional flow, and total superficial velocity. Surfactant-solution type and concentration are also important but they were the same for all experiments.

Foam Propagation. We monitored the texture of the foam across the fracture at steady-state flow conditions, using images captured at different distances from the injection port.

Sample 1. Sample 1 has the widest hydraulic aperture $d_{\mathrm{h}}$ (Table 1) and many asperities. We analyzed foam texture for $f_{\mathrm{g}}=$ 0.45 and $u_{\mathrm{t}}=0.0012 \mathrm{~m} / \mathrm{s}$. The analysis shows that gas enters the model and propagates about 6 to $10 \mathrm{~cm}$ as a continuous phase (Figure 15, image 1). This is evident in the average bubble size and the number of bubbles per unit area. The continuous gas phase starts to break up into relatively smaller gas bubbles by lamella division as discussed previously. We did not observe significant changes in foam texture in sections 2 and 3 (Figure 15 , images 2 and 3 ). However, in the last section the bubble size became somewhat smaller than the average size of the pore, 7.3 $\mathrm{mm}^{2}$, determined from the $2 \mathrm{D}$ network analysis (Figure 15, image 4). Table 2 presents the statistics from the image analysis for Sample 1. We believe that the foam has not reached a final local-equilibrium state in this case. The wide aperture strongly 

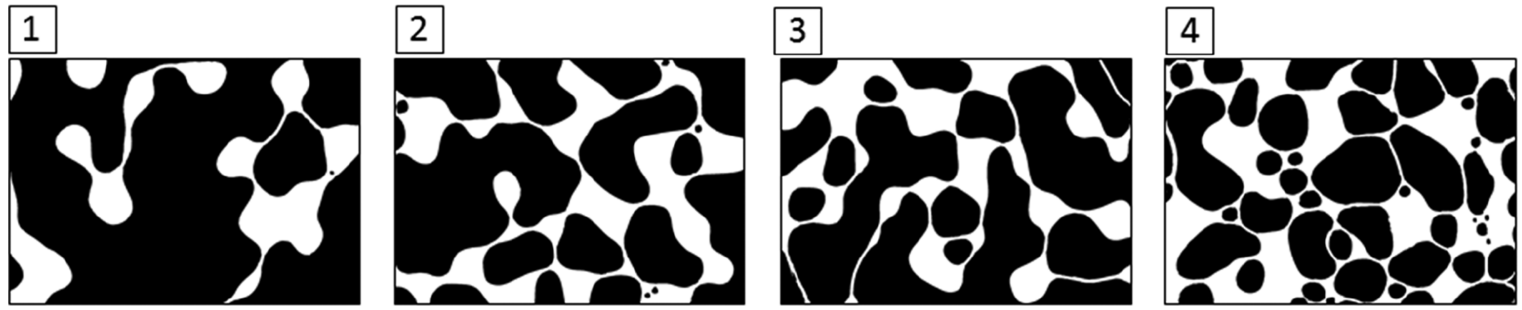

Figure 15. Sample 1: Foam texture vs distance at $f_{\mathrm{g}}=0.45$ and $u_{\mathrm{t}}=0.0012 \mathrm{~m} / \mathrm{s}$. Image size is $2.5 \times 1.7 \mathrm{~cm}^{2}$; black is gas and white is water. The images were captured once the pressure gradient had stabilized. Gas is initially continuous and bubbles are generated by lamella division as gas propagates through the fracture. Bubble size becomes smaller than the pore-body size toward the last section of the model fracture. The number of bubbles per unit area significantly increased in section 4 .

Table 2. Sample 1: Image-Analysis Statistics. $f_{\mathrm{g}}=0.45$ and $u_{\mathrm{t}}=$ $0.0012 \mathrm{~m} / \mathrm{s}$

\begin{tabular}{lllll}
\multicolumn{1}{c}{ section } & \multicolumn{1}{c}{1} & \multicolumn{1}{c}{2} & \multicolumn{1}{c}{3} & \multicolumn{1}{c}{4} \\
\hline distance from inlet, $\mathrm{mm}$ & 60 & 150 & 230 & 360 \\
average bubble size, $\mathrm{mm}^{2}$ & 58.06 & 14.23 & 17.66 & 4.92 \\
bubble size, std. dev., $\mathrm{mm}^{2}$ & 107.6 & 20.63 & 21.22 & 6.19 \\
number of bubbles per unit area & 5 & 21 & 17 & 55 \\
\hline
\end{tabular}

influences the entrance region, lengthening it considerably. This effect was also clear in the pressure response as discussed in the next section.

Sample 2. Sample 2 has a regular pattern in its roughness, with much smaller $d_{\mathrm{h}}$ and $L_{\mathrm{p}}$ than sample 1 . Foam was generated mainly by snap-off and lamella division. In a manner similar to sample 1, we captured images at different distances from the injection point. In this model fracture, unlike the others, there was converging flow toward a single outlet port, so the last section is not included in the foam-texture analysis. ${ }^{28}$ This analysis was performed at $f_{\mathrm{g}}=0.37$ and $u_{\mathrm{t}}=0.0021 \mathrm{~m} / \mathrm{s}$. The foam gets finer as it propagates through the facture, due to snapoff. The average bubble size decreases and the number of bubbles per unit area in section 3 is almost double that in section 1 (Figure 16 and Table 3 ). The two tests were not at identical $f_{\mathrm{g}}$ and $u_{\mathrm{t}}$, but the fact that in sample 2 bubble size is so much smaller than in sample 1 suggests that both $d_{\mathrm{h}}$ and $L_{\mathrm{p}}$ play a role in foam texture. By section 3 of sample 2 the average bubble size was much smaller than the pore body of the sample, which is $0.50 \mathrm{~mm}^{2}$.

Sample 3. Sample 3 has the second largest $d_{\mathrm{h}}$ and the largest $L_{\mathrm{p}}$ (Table 1), and foam was generated by both snap-off and lamella division as discussed earlier. Foam-texture analysis was performed at $f_{\mathrm{g}}=0.60$ and $u_{\mathrm{t}}=0.0013 \mathrm{~m} / \mathrm{s}$ and shows that the
Table 3. Sample 2: Image-Analysis Statistics. $f_{\mathrm{g}}=0.37, u_{\mathrm{t}}=$ $0.0021 \mathrm{~m} / \mathrm{s}$

\begin{tabular}{|llll}
\hline \multicolumn{1}{c}{ section } & \multicolumn{1}{c}{1} & \multicolumn{1}{c}{2} & \multicolumn{1}{c}{3} \\
\hline distance from inlet, $\mathrm{mm}$ & 20 & 120 & 270 \\
average bubble size, $\mathrm{mm}^{2}$ & 0.250 & 0.138 & 0.081 \\
bubble size, std. dev., $\mathrm{mm}^{2}$ & 0.205 & 0.125 & 0.056 \\
number of bubbles per unit area & 165 & 217 & 303 \\
\hline
\end{tabular}

average bubble size decreases and the number of bubbles in section 4 is 12 times greater than in section 1 (Figure 17). The average pore-body size of this sample is $32.9 \mathrm{~mm}^{2}$, which is significantly larger than the average bubble size of $4.47 \mathrm{~mm}^{2}$ observed toward the end of the fracture (Table 4). Similarly to sample 1, we observed large gas bubbles near the entrance, and only toward the last section did the foam bubbles become finer.

Sample 4 . Sample 4 is characterized by a small $d_{\mathrm{h}}$ and a large $L_{\mathrm{p}}$. Foam was generated by both snap-off and lamella division in this sample. Foam-texture analysis was performed at $f_{\mathrm{g}}=0.70$ and $u_{\mathrm{t}}=0.0016 \mathrm{~m} / \mathrm{s}$. This analysis shows that a considerable number of lamellae have been created in section 2, as compared to samples 1 and 3 , where the $d_{\mathrm{h}}$ values were much larger, 670 and $330 \mu \mathrm{m}$ respectively (Figure 18). Foam propagates through the fracture and is refined as it flows downstream. The average pore-body size in this sample is $13.2 \mathrm{~mm}^{2}$, compared to the average bubble size of $0.14 \mathrm{~mm}^{2}$ observed toward the end of the fracture (Table 5). The small $d_{\mathrm{h}}$ in this sample has influenced the bubble size greatly, making a significant number of bubbles within a short distance of fluid entry.

In addition to the original Sample 4 , with $d_{\mathrm{h}}=51 \mu \mathrm{m}$, samples $4 \mathrm{a}$ and $4 \mathrm{~b}$ have $d_{\mathrm{h}}=72$ and $207 \mu \mathrm{m}$, respectively. We made a comparison of foam texture at the same distance from the injection port once a stable pressure gradient was observed in
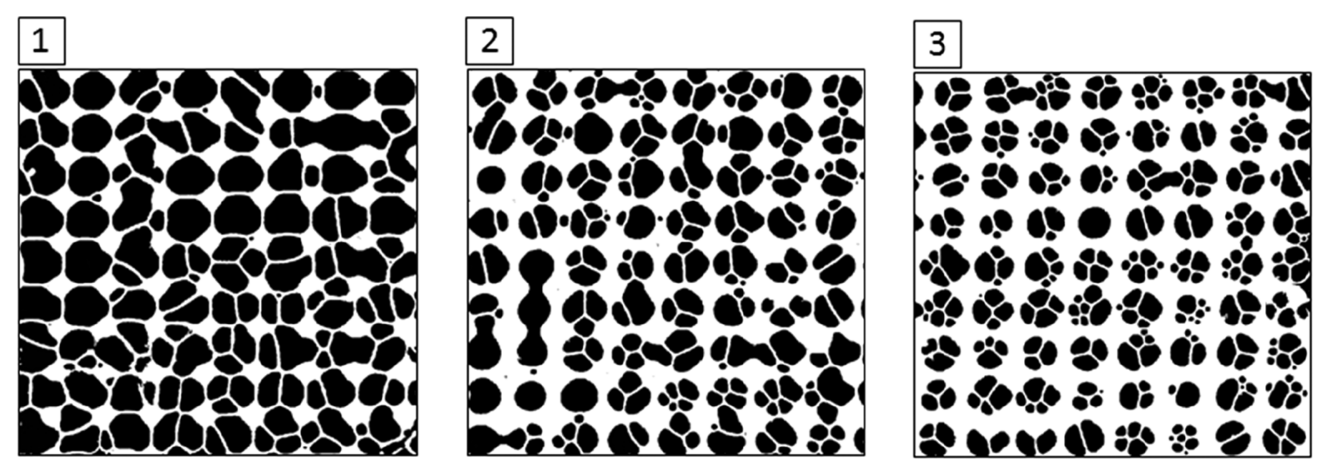

Figure 16. Sample 2: Foam texture vs distance at $f_{\mathrm{g}}=0.37, u_{\mathrm{t}}=0.0021 \mathrm{~m} / \mathrm{s}$; black is gas and white is water. The images are captured during stabilized pressure gradient. Image size $0.8 \times 0.77 \mathrm{~cm}^{2}$. Foam-texture analysis shows that the average bubble size decreases and the number of bubbles in section 3 is almost double that in section 1. 
1

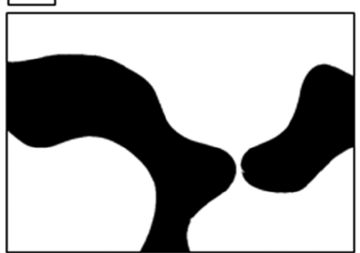

2

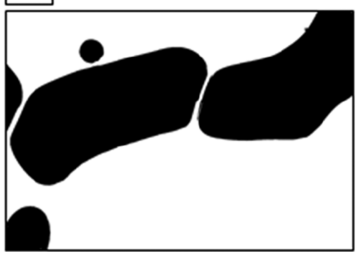

3

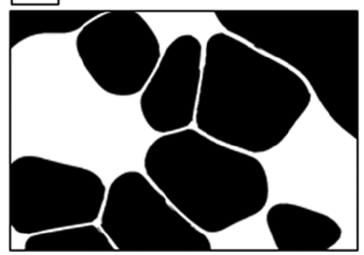

4

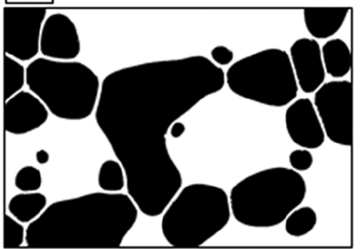

Figure 17. Sample 3: Foam texture vs distance at $f_{\mathrm{g}}=0.60, u_{\mathrm{t}}=0.0013 \mathrm{~m} / \mathrm{s}$; black is gas and white is water. The images are captured during stabilized pressure gradient. Image size $1.7 \times 1.1 \mathrm{~cm}^{2}$. The number of bubbles is 12 times greater in section 4 than in section 1 .

Table 4. Sample 3: Image-Analysis Statistics. $f_{\mathrm{g}}=0.60, u_{\mathrm{t}}=$ $0.0013 \mathrm{~m} / \mathrm{s}$

\begin{tabular}{lllll}
\multicolumn{1}{c}{ section } & \multicolumn{1}{c}{1} & \multicolumn{1}{c}{2} & \multicolumn{1}{c}{3} & \multicolumn{1}{c}{4} \\
\hline distance from inlet, $\mathrm{mm}$ & 60 & 150 & 230 & 360 \\
average bubble size, $\mathrm{mm}^{2}$ & 34.24 & 15.73 & 12.99 & 4.47 \\
bubble size, std. dev., $\mathrm{mm}^{2}$ & 19.55 & 18.72 & 6.93 & 5.63 \\
number of bubbles per unit area & 2 & 5 & 10 & 24 \\
\hline
\end{tabular}

each case. This test was conducted at fixed $f_{\mathrm{g}}=0.45$ and $u_{\mathrm{t}}=$ $0.0032 \mathrm{~m} / \mathrm{s}$. Coarser-textured foam is evident as $d_{\mathrm{h}}$ increases (Figure 19), and fewer snap-off events are observed at $d_{\mathrm{h}}$ of 207 $\mu \mathrm{m}$. The increase in bubble volume is greater than the increase in bubble area as aperture increases (Table 8 ). The average bubble size increases with increasing $d_{\mathrm{h}}$ (Table 6).

Sample 5. Foam was generated solely by lamella division in sample 5 . The foam-texture analysis was performed at $f_{g}=0.46$ and $u_{\mathrm{t}}=0.0007 \mathrm{~m} / \mathrm{s}$. Initially, the gas forms a continuous phase, and foam bubbles are created as it propagates downstream. The average pore-body size of this sample is $4.00 \mathrm{~mm}^{2}$, compared to the average bubble size of $0.53 \mathrm{~mm}^{2}$ observed toward the end of the fracture (Table 7). Foam is generated by a similar mechanism in both samples 1 and 5. The two samples have roughly the same $L_{\mathrm{p}}$; however, the foam texture is different in the two samples due to the difference in apertures (Figure 20).

Samples 5a and $5 \mathrm{~b}$ have $d_{\mathrm{h}}=145$ and $170 \mu \mathrm{m}$, respectively. Tests were conducted at fixed $f_{g}=0.45$ and $u_{t}=0.0022 \mathrm{~m} / \mathrm{s}$ (Figure 21). The image analysis reveals a similar behavior to Sample 4, with coarser-textured foam observed as $d_{\mathrm{h}}$ increases. The average bubble size increases, and the number of bubbles decreases, as $d_{\mathrm{h}}$ increases (Table 8).

Comparison of Samples. These experiments demonstrate the effect of $d_{\mathrm{h}}$ and $L_{\mathrm{p}}$ on foam texture. In all the samples, foam becomes finer as it propagates through the fracture. We cannot confirm that foam has reached the final local equilibrium state by the time it reaches the outlet in these experiments. Fine-textured foam was observed in the fractures with the smallest apertures
Table 5. Sample 4: Image-Analysis Statistics. $f_{\mathrm{g}}=0.70, u_{\mathrm{t}}=$ $0.0016 \mathrm{~m} / \mathrm{s}$

\begin{tabular}{lcccc}
\multicolumn{1}{c}{ section } & 1 & 2 & 3 & 4 \\
distance from inlet, mm & 60 & 150 & 230 & 360 \\
average bubble size, $\mathrm{mm}^{2}$ & $\mathrm{NA}$ & 0.36 & 0.26 & 0.14 \\
bubble size, std. dev., $\mathrm{mm}^{2}$ & $\mathrm{NA}$ & 0.47 & 0.40 & 0.16 \\
number of bubbles per unit area & $\mathrm{NA}$ & 207 & 216 & 479 \\
\hline
\end{tabular}

and course-textured foam in the fractures with the largest apertures. Samples with approximately similar apertures (samples 2 and 4) and different $L_{\mathrm{p}}$ show two distinctly different textures: smaller bubbles in the fracture with smaller pores, though the bubbles are smaller than the pores in both cases. Foam occupies the pore bodies differently, based on the shape of the pore bodies.

Foam-Quality Scans. Foam-quality scans were carried out on these model fractures, by holding $u_{\mathrm{t}}$ constant and varying $f_{\mathrm{g}}$. The surfactant solution and nitrogen were coinjected into the initially water-saturated fracture, and the pressure gradient across the four sections was recorded until stabilization of pressure gradient was achieved. Significant pressure oscillations were observed in these tests, and larger oscillations were evident at high $f_{\mathrm{g}}$. These oscillations reduce the time-average foam apparent viscosity. In nonfractured porous media the foam behavior at high quality is believed to reflect the destruction of foam at the limiting capillary pressure. ${ }^{38-40}$ We did not observe significant foam coalescence in any of our samples at any tested foam qualities. In our experiments oscillations in pressure gradient reflect fluctuations in foam generation. ${ }^{28}$

We selected the fourth section of each sample, except for Sample 2, as the basis for our analysis of the pressure behavior. In Sample 2, we used the third section, due to the converging flow toward the outlet port in the fourth section. We averaged the pressure gradient over the period of stabilization for each foam quality. The injected gas volume was corrected to the pressure at the middle of the fracture.
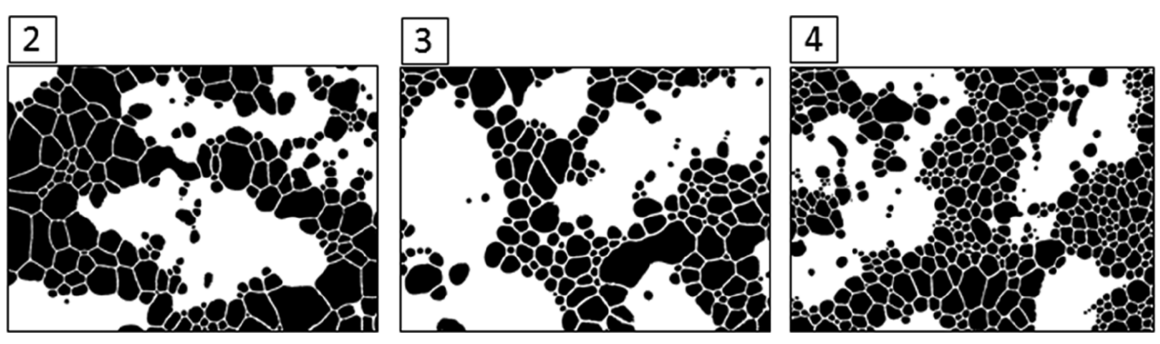

Figure 18. Sample 4: Foam texture vs distance at $f_{\mathrm{g}}=0.70, u_{\mathrm{t}}=0.0016 \mathrm{~m} / \mathrm{s}$. Black is gas and white is water. The images were captured during stabilized pressure gradient. Image size is $1.4 \times 1.0 \mathrm{~cm}^{2}$. An image of section 1 was not available for the analysis. Among our samples, sample 4 has the smallest $d_{\mathrm{h}}$, $51 \mu \mathrm{m}$. A considerably greater number of lamellae have been created in section 2 as compared to samples 1 and 3 , where $d_{\mathrm{h}}=670$ and $330 \mu \mathrm{m}$, respectively. 

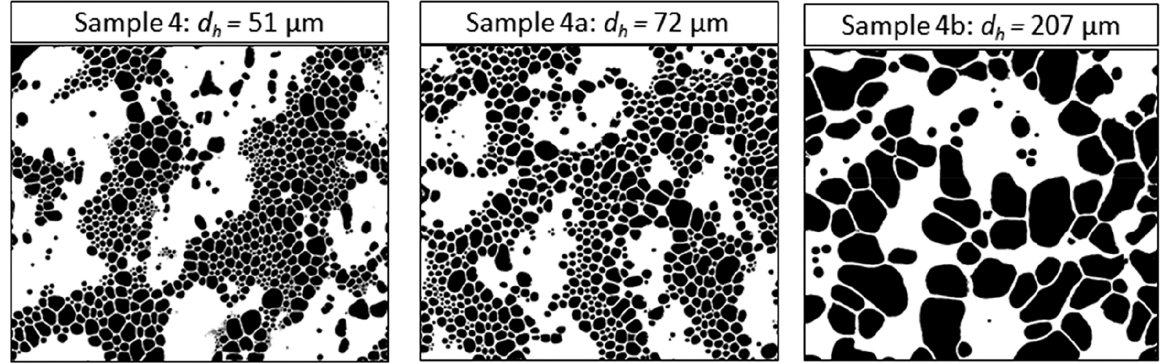

Figure 19. Samples 4, 4a, $4 \mathrm{~b}$ : foam texture versus $d_{\mathrm{h}}$ at $f_{\mathrm{g}}=0.45$ and $u_{\mathrm{t}}=0.0032 \mathrm{~m} / \mathrm{s}$. Black is gas and white is water. The images were captured during stabilized pressure gradient. The image size is $1.7 \times 1.5 \mathrm{~cm}^{2}$. The correlation length of roughness and $L_{\mathrm{p}}$ are the same in all three fractures. Images are captured $36 \mathrm{~cm}$ from the inlet. The analysis shows that for fixed $L_{\mathrm{p}}$ the average bubble size increases with increasing $d_{\mathrm{h}}$.

Table 6. Samples 4, 4a, 4b: Effect of Hydraulic Aperture on Foam Texture at Fixed $L_{\mathrm{p}}$

\begin{tabular}{lllc}
\multicolumn{1}{c}{ parameter } & sample 4 & sample 4a & sample 4b \\
hydraulic aperture $d_{\mathrm{h}}, \mu \mathrm{m}$ & 51 & 72 & 207 \\
average bubble size, $\mathrm{mm}^{2}$ & 0.097 & 0.148 & 1.37 \\
bubble size, std. dev., $\mathrm{mm}^{2}$ & 0.114 & 0.133 & 1.32 \\
number of bubbles per unit area & 972 & 750 & 78
\end{tabular}

Table 7. Sample 5: Image-Analysis Statistics. $f_{\mathrm{g}}=0.46, u_{\mathrm{t}}=$ $0.0007 \mathrm{~m} / \mathrm{s}$

\begin{tabular}{|lcccc}
\multicolumn{1}{c}{ section } & 1 & 2 & 3 & 4 \\
distance from inlet, $\mathrm{mm}$ & 60 & 150 & 230 & 360 \\
average bubble size, $\mathrm{mm}^{2}$ & 2.48 & 0.66 & 0.60 & 0.53 \\
bubble size, std. dev., $\mathrm{mm}^{2}$ & 7.84 & 0.57 & 0.48 & 0.36 \\
number of bubbles per unit area & 37 & 160 & 176 & 194
\end{tabular}

We tested foam mobility as a function of foam quality $f_{\mathrm{g}}$ for four total superficial velocities $u_{\mathrm{v}}$ for three of the model fractures (samples 2,4 , and 5 ). Foam quality $f_{\mathrm{g}}$ was varied in a random sequence, to avoid misinterpreting the possible effects of hysteresis that might occur in the case of sequential increase or decrease in $f_{\mathrm{g}}$. For sample 1 , with $d_{\mathrm{h}}=670 \mu \mathrm{m}$, foam was observed only toward the outlet of the model. The recorded pressure gradient $\nabla p$ was only a few $\mathrm{mbar} / \mathrm{m}$ (a few hundred $\mathrm{Pa}$ / $\mathrm{m}$ ), with large oscillations (Figure 22). Although we tested flow at different values of $u_{\mathrm{t}}$ and $f_{\mathrm{g}}$, we were not able to obtain a meaningful foam-quality scan on this sample due to large oscillation at a very low pressure gradient. Therefore, the uncertainty and variability in $\nabla p$ was too great for meaningful analysis, especially at higher $f_{\mathrm{g}}$. Similarly, for sample 3 , with the second largest $d_{\mathrm{h}}$ of $330 \mu \mathrm{m}$, we did not obtain a foam-quality scan. The recorded pressure gradient was an average of 34.56 $\mathrm{mbar} / \mathrm{m}$ with significant fluctuations (Figure 23), even at low $f_{\mathrm{g}}$. It was harder to create foam, reduce gas mobility, and increase $\nabla p$ significantly with wider apertures.
Foam-quality scans were successfully carried out for Samples 2 , 4, and 5. In general, as the velocity increases, the pressure gradient increases; however, the increase is not proportional to $u_{\mathrm{t}}$. Figures 24,25 , and 26 show the foam-quality scans of samples 2 , 4, and 5, respectively. The effect of $L_{\mathrm{p}}$ or the correlation length on the pressure gradient is made clear by comparing samples 2 and 4 , which have similar hydraulic aperture $d_{\mathrm{h}}$ (Table 1 ). The overall pressure gradient for sample 2 is greater than that for sample 4 . We believe this occurs because there is a throat which both contributes to foam generation and restricts bubble flow every $800 \mu \mathrm{m}$ in sample 2 (Table 1 ). The throat apertures are somewhat greater in sample 4, but the pores are also five times longer.

Figures 24 to 26 indicate the range of shear-thinning behavior in these three samples. For sample 2, at injected gas fraction $f_{\mathrm{g}}=$ 0.25 , pressure gradient $\nabla p$ increases only about $14 \%$ upon an increase in total superficial velocity by a factor of 5: in effect, a power-law exponent $n$ less than 0.1 For $f_{\mathrm{g}}=0.75, n$ is about 0.43 . For sample 2 , at $f_{\mathrm{g}}=0.3, n \sim 0.3$, and at $f_{\mathrm{g}}=0.7, n \sim 0.85$, nearly Newtonian. For sample 5 , at $f_{\mathrm{g}}=0.3, n \sim 0.26$, and at $f_{\mathrm{g}}=0.7, n \sim$ 0.83 .

Central to the understanding of flow in nonfractured porous media is the existence of two distinct foam-flow regimes, corresponding to high foam quality and low foam quality. ${ }^{40-44}$ The pressure gradient is independent of liquid velocity in the low-quality regime and independent of gas velocity in the highquality regime. In sample 2 these two regimes were observed. Figure 27 shows the pressure-gradient contours for sample 2 . Pressure-gradient data for samples 4 and 5 are shown in Figures 28 and 29 , respectively.

The same two foam-flow regimes were observed in sample 5 . For sample 4, all of the data would correspond to a transition region between the high- and low-quality regimes. The transition between regimes is sensitive to both the nature of the porous medium and the ability of the surfactant to stabilize foam. ${ }^{40}$ Given the absence of evidence of either flow regime in so

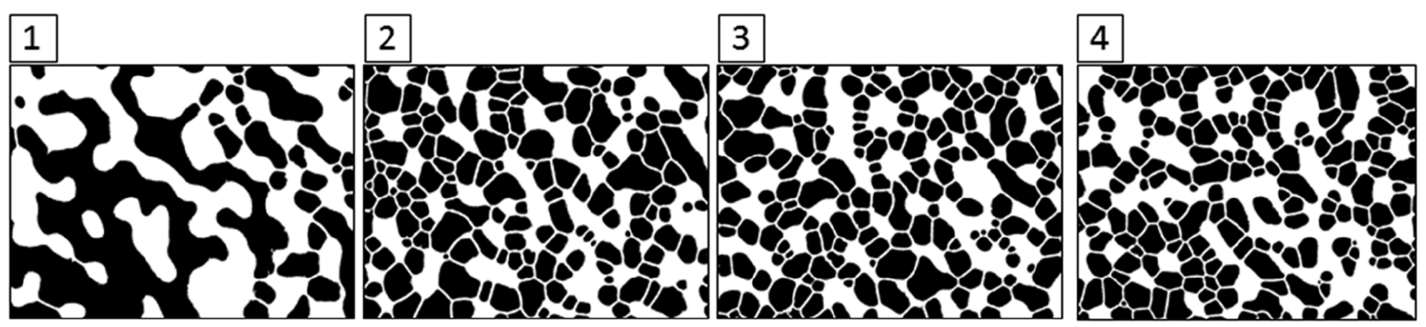

Figure 20. Sample 5: Foam texture vs distance at $f_{\mathrm{g}}=0.46, u_{\mathrm{t}}=0.0007 \mathrm{~m} / \mathrm{s}$; black is gas and white is water. The images are captured during stabilized pressure gradient. Image size $1.6 \times 1.6 \mathrm{~cm}^{2}$. Initially the gas forms a continuous phase, then bubbles are created by lamella division. 

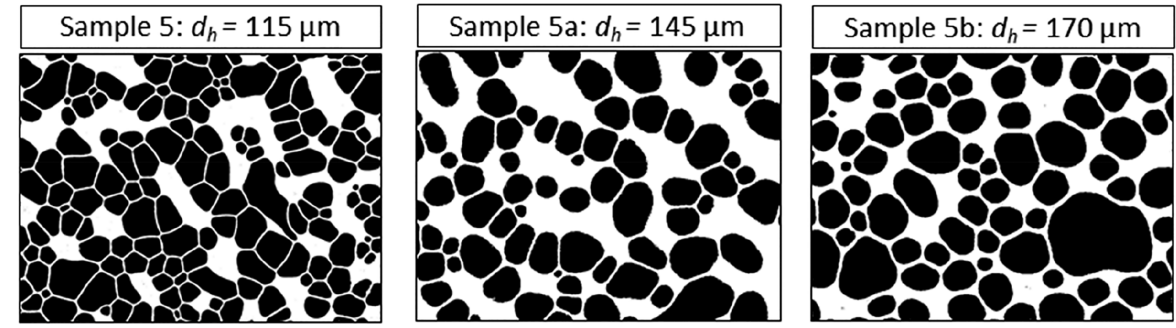

Figure 21. Samples 5, 5a, 5b: Foam texture versus $d_{\mathrm{h}}$ at $f_{\mathrm{g}}=0.45$ and $u_{\mathrm{t}}=0.0022 \mathrm{~m} / \mathrm{s}$. Black is gas and white is water. The images are captured during stabilized pressure gradient. The image size is $1.1 \times 0.86 \mathrm{~cm}^{2}$. The roughness scale, or $L_{\mathrm{p}}$, is the same for all three fractures. Images are captured $36 \mathrm{~cm}$ from the inlet. The analysis shows that for a fixed $L_{\mathrm{p}}$ the average bubble size increases as $d_{\mathrm{h}}$ increases.

Table 8. Samples 5, 5a, 5b: Effect of Hydraulic Aperture on Foam Texture at Fixed $L_{\mathrm{p}}$

\begin{tabular}{|llcl}
\multicolumn{1}{c}{ parameter } & sample 5 & sample 5a & sample 5b \\
\hline hydraulic aperture $d_{\mathrm{h}}, \mu \mathrm{m}$ & 115 & 145 & 170 \\
average bubble size, $\mathrm{mm}^{2}$ & 0.468 & 0.74 & 0.943 \\
bubble size, std. dev., $\mathrm{mm}^{2}$ & 0.343 & 0.438 & 1.02 \\
number of bubbles per unit area & 120 & 55 & 54 \\
\hline
\end{tabular}

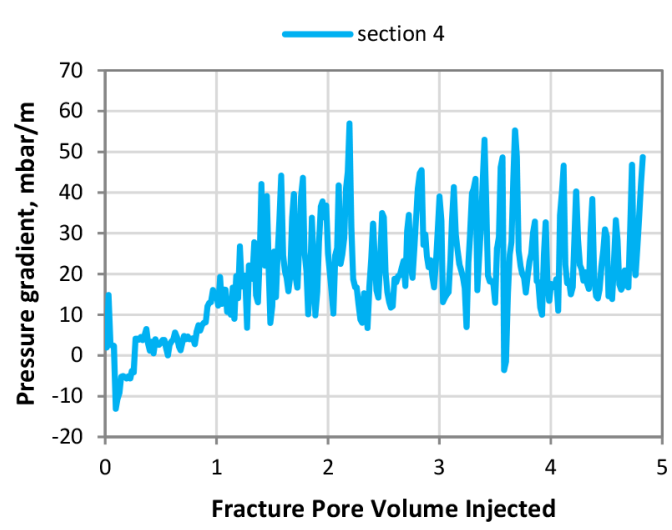

Figure 22. Sample 1: $\left(d_{\mathrm{h}}=670 \mu \mathrm{m}\right)$; section 4 pressure gradient at $u_{\mathrm{t}}=$ $0.0012 \mathrm{~m} / \mathrm{s}$ and $f_{\mathrm{g}}=0.45$. No foam-quality scan could be carried out due to a small magnitude of pressure gradient and large oscillations.

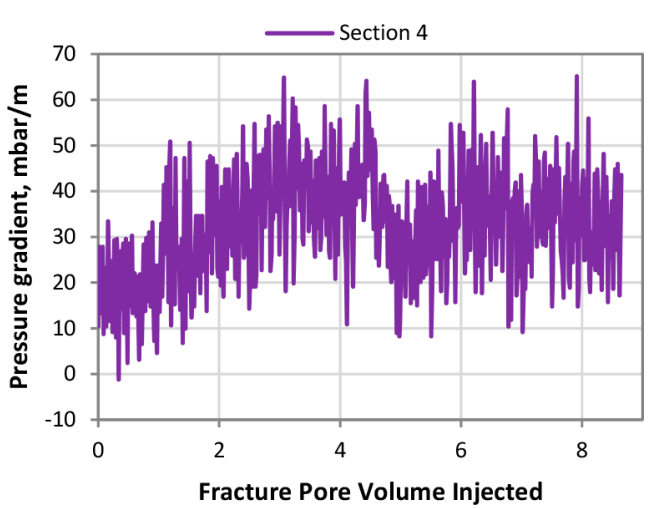

Figure 23. Sample 3: $\left(d_{\mathrm{h}}=330 \mu \mathrm{m}\right)$; section 4 pressure gradient at $u_{\mathrm{t}}=$ $0.0013 \mathrm{~m} / \mathrm{s}$ and $f_{\mathrm{g}}=0.45$. No foam-quality scan could be carried out due to the small magnitude of pressure gradient and large oscillations.

wide a scan of foam quality (see Figure 28), it may well be that the two regimes do not apply to this foam in this fracture.

We do not know the reason for this difference. Sample 4 has narrower aperture than sample 5 and similar aperture to sample 2 (Table 1). It is possible that foam has not reached local

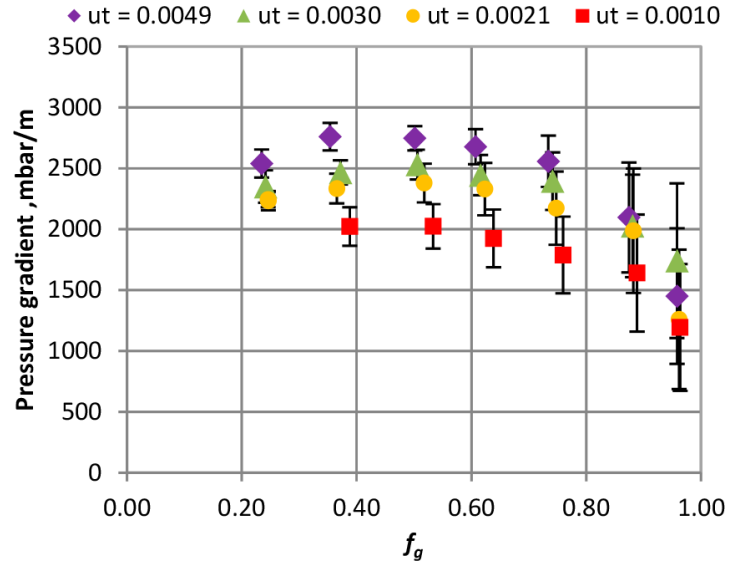

Figure 24. Sample 2: foam-quality scans at different total superficial velocities $u_{\mathrm{t}}(\mathrm{m} / \mathrm{s})$. The error bars in the data reflect oscillations in pressure gradient.

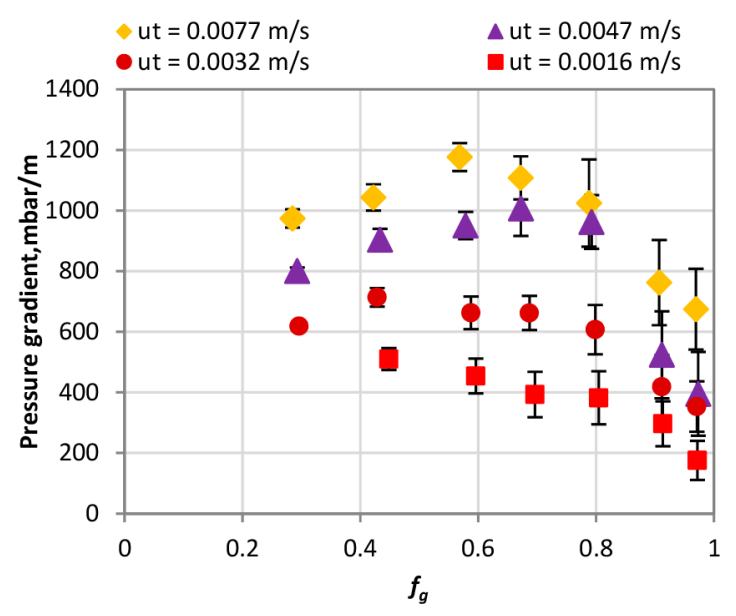

Figure 25. Sample 4: foam-quality scans at different total superficial velocities $u_{\mathrm{t}}(\mathrm{m} / \mathrm{s})$. The error bars in the data reflect oscillations in pressure gradient.

equilibrium with the fracture, since texture is still rapidly changing in the fourth section (Figure 18, Table 5).

As $d_{\mathrm{h}}$ increases from 51 to $72 \mu \mathrm{m}$ (samples 4 and $4 \mathrm{a}$ ), the pressure gradient increases for all the foam qualities tested. We do not have an explanation for this increase in pressure gradient. The bubbles are larger in sample 4a (Table 6). However, when $d_{\mathrm{h}}$ increases further to $207 \mu \mathrm{m}$ (sample $4 \mathrm{~b}$ ), the pressure gradient decreases substantially (Figure 30 ).

As $d_{\mathrm{h}}$ increases from 115 to $145 \mu \mathrm{m}$ (samples 5 and $5 \mathrm{a}$ ), the pressure gradient substantially decreases. An additional 17\% increase in $d_{\mathrm{h}}$ yields only a marginal decrease in pressure 
ut $=0.0036 \mathrm{~m} / \mathrm{s} \quad \Delta$ ut $=0.0022 \mathrm{~m} / \mathrm{s} \quad$ ut $=0.0015 \mathrm{~m} / \mathrm{s} \quad$ ut $=0.0007 \mathrm{~m} / \mathrm{s}$

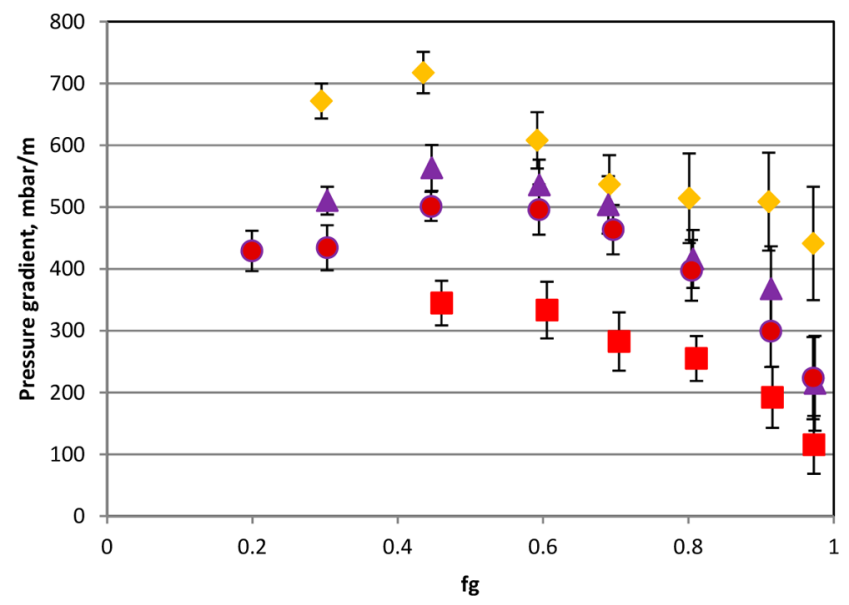

Figure 26. Sample 5: foam-quality scans at different total superficial $u_{\mathrm{t}}$ velocities $(\mathrm{m} / \mathrm{s})$. The error bars in the data reflect oscillations in pressure gradient.

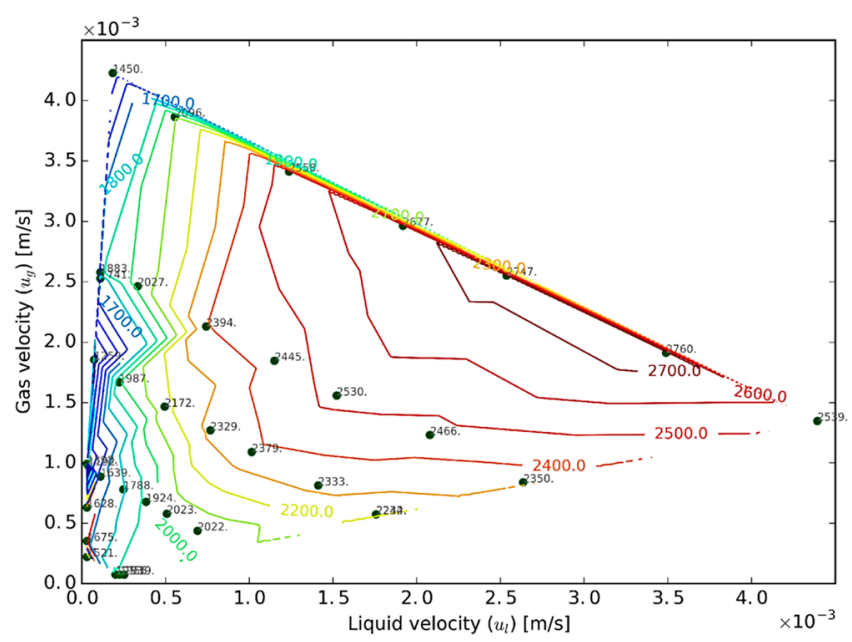

Figure 27. Sample 2: pressure-gradient $(\mathrm{mbar} / \mathrm{m})$ as a function of superficial velocities of gas and liquid.

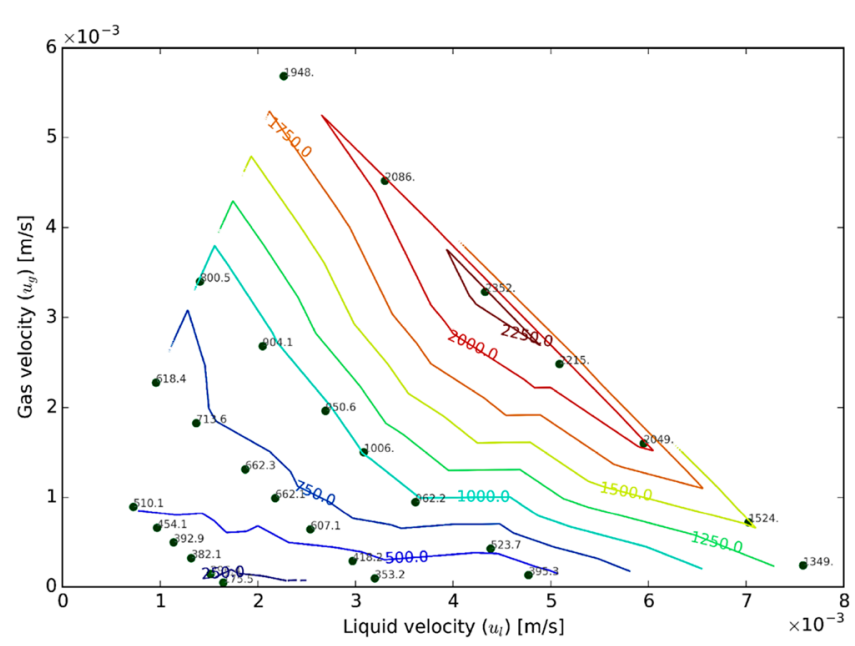

Figure 28. Sample 4: pressure-gradient $(\mathrm{mbar} / \mathrm{m})$ as a function of superficial velocities of gas and liquid.

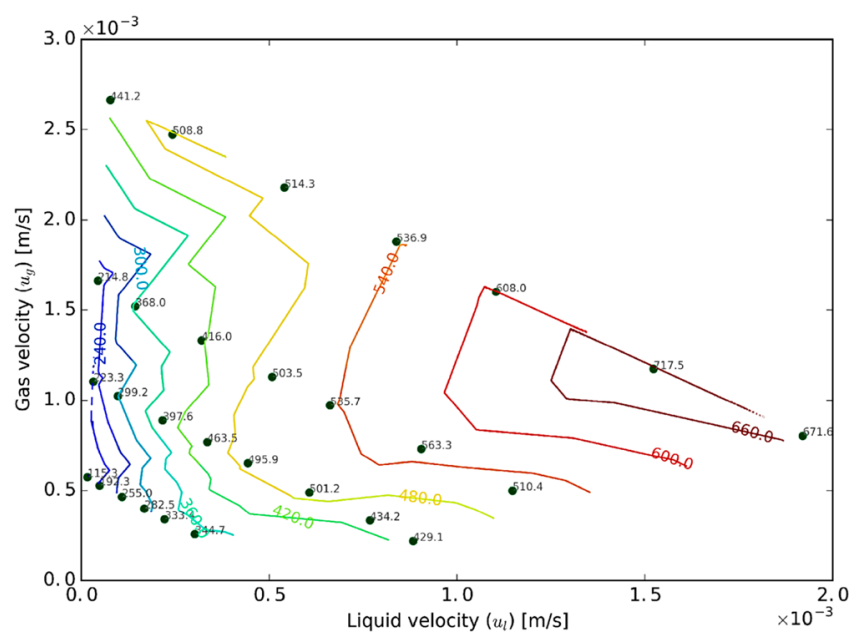

Figure 29. Sample 5: pressure-gradient $(\mathrm{mbar} / \mathrm{m})$ as a function of superficial velocities of gas and liquid.

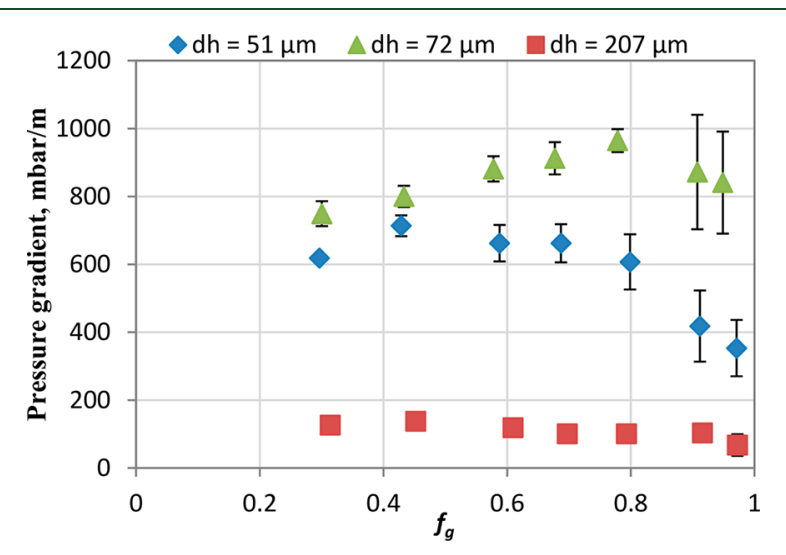

Figure 30. Samples 4, 4a, and 4b: foam-quality scans at different values of $d_{\mathrm{h}}$. The error bars in the data reflect oscillations in pressure gradient.

gradient (Figure 31). This appears to be related to the number of bubbles in the two cases. The number of bubbles for $d_{\mathrm{h}}=170 \mu \mathrm{m}$ decreases slightly compared to the case at $d_{\mathrm{h}}=145 \mu \mathrm{m}$.

Table 9 summarizes the pressure-gradient results. For this comparison we selected $f_{g}$ and $u_{t}$ to be in the vicinity of 0.45 and $0.0025 \mathrm{~m} / \mathrm{s}$ for all the samples. Samples 2 and 5 deviate the most

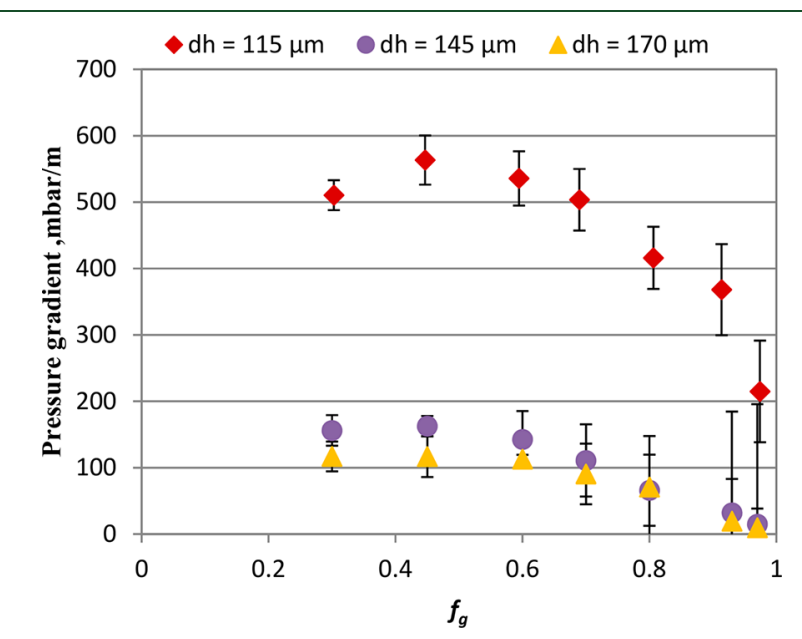

Figure 31. Samples 5, 5a, and 5b: foam-quality scans at different $d_{\mathrm{h}}$. The error bars in the data reflect oscillations in pressure gradient. 
Table 9. Summary of Pressure-Gradient Results with Respect to Variation in $d_{\mathrm{h}}$ and $L_{\mathrm{p}}$ at Specific Flow Conditions

\begin{tabular}{|c|c|c|c|c|c|c|c|c|}
\hline sample no. & $d_{\mathrm{h}}, \mu \mathrm{m}$ & $u_{\mathrm{t}}, \mathrm{m} / \mathrm{s}$ & $f_{\mathrm{g}}$ & $\nabla P($ foam $), \mathrm{mbar} / \mathrm{m}$ & $\nabla P($ water $), \mathrm{mbar} / \mathrm{m}$ & MRF & $L_{\mathrm{p}}, \mu \mathrm{m}$ & bubble size, $\mathrm{mm}^{2}$ \\
\hline 1 & 670 & 0.0025 & 0.45 & 35 & 0.67 & 52 & 2661 & NA \\
\hline 2 & 66 & 0.0030 & 0.38 & 2466 & 82.6 & 30 & 819 & 0.089 \\
\hline 3 & 330 & 0.0025 & 0.45 & 52 & 2.75 & 19 & 5156 & 4.315 \\
\hline 4 & 51 & 0.0032 & 0.45 & 713 & 142.6 & 5 & 4415 & 0.097 \\
\hline $4 a$ & 72 & 0.0032 & 0.45 & 800 & 80 & 10 & 4415 & 0.145 \\
\hline $4 b$ & 207 & 0.0032 & 0.45 & 137 & 9.1 & 15 & 4415 & 1.37 \\
\hline 5 & 115 & 0.0022 & 0.45 & 563 & 29 & 19.4 & 2421 & 0.468 \\
\hline $5 a$ & 145 & 0.0022 & 0.45 & 162 & 13 & 12.4 & 2421 & 0.74 \\
\hline $5 b$ & 170 & 0.0022 & 0.45 & 117 & 13 & 9 & 2421 & 0.943 \\
\hline
\end{tabular}

from the selected $u_{t}$, but based on the shear-thinning behavior shown in Figures 24 and 26, we do not expect significant change in the values of $\nabla P_{\text {foam. }}$. Sample 2 showed the highest value of $\nabla P$ with foam. We believe this reflects the small $d_{\mathrm{h}}$ and $L_{\mathrm{p}}$ (compared to sample 4 , with similar $d_{\mathrm{h}}$ ). The calculated mobility-reduction factor of foam compared to single-phase flow of water (MRF) is based on the single-phase flow experiments used to determine $d_{\mathrm{h}}$ for each sample. ${ }^{35}$ Figure 32 shows how

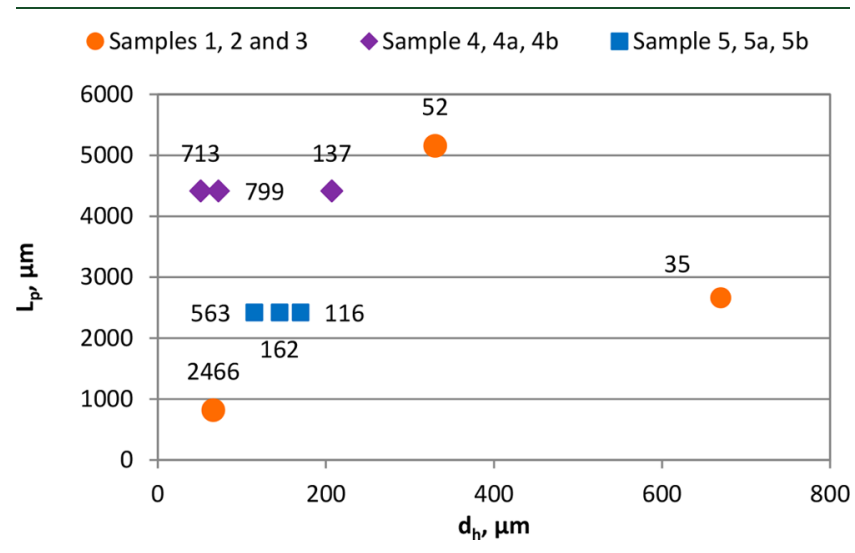

Figure 32. Effect of pore-geometry parameters $d_{\mathrm{h}}$ and $L_{\mathrm{p}}$ on $\nabla P(\mathrm{mbar} /$ $\mathrm{m}$ ) with foam (numbers printed next to data points). $L_{\mathrm{p}}$ was fixed in samples 4, 4a, and 4B and in and 5, 5a, and 5b.

pressure gradient responds to $d_{\mathrm{h}}$ and $L_{\mathrm{p}}$. Pressure gradient is much greater for narrower fractures. It also increases with decreasing $L_{\mathrm{p}}$, though less dramatically. There is no simple trend between MRF and either $d_{\mathrm{h}}$ or $L_{\mathrm{p}}$ alone (Figures 33 and 34). Because MRF is a comparison to single-phase laminar flow, if $\nabla p$ decreases with increasing $d_{\mathrm{h}}$ less than $\left(d_{\mathrm{h}}\right)^{(-3)}$, MRF increases.

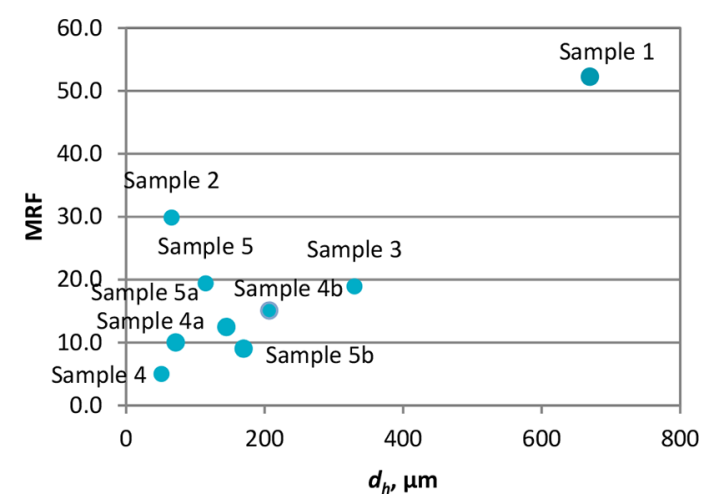

Figure 33. MRF versus $d_{\mathrm{h}}$ for all samples.

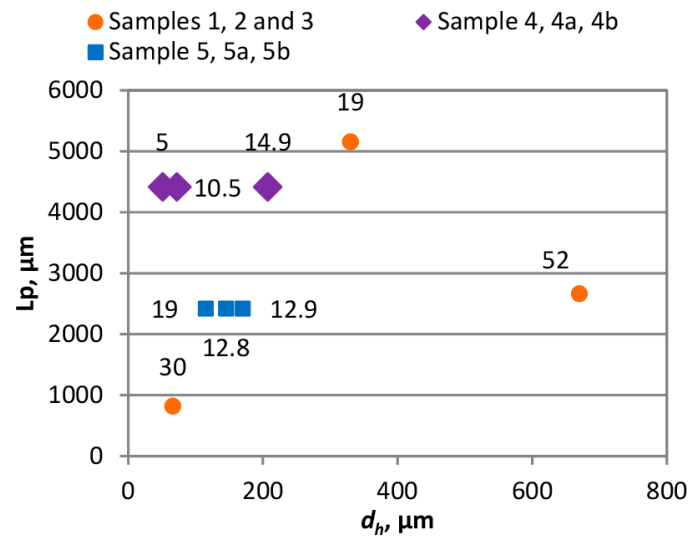

Figure 34. Effect of $d_{\mathrm{h}}$ and $L_{\mathrm{p}}$ on MRF (numbers printed next to data points). $L_{\mathrm{p}}$ was fixed in samples $4,4 \mathrm{a}$, and $4 \mathrm{~b}$ and in samples $5,5 \mathrm{a}$, and $5 b$.

Fracture Geometry and Foam Properties. Appendix B presents a characterization of expected foam-generation mechanisms based on fracture geometry, characterized in three dimensionless groups: the ratio of throat width to throat aperture $\left(w_{\mathrm{t}} / d_{\mathrm{t}}\right)$, the ratio of body aperture to throat aperture $\left(d_{\mathrm{b}} / d_{\mathrm{t}}\right)$, and the ratio of body width to body aperture $\left(w_{\mathrm{b}} / d_{\mathrm{b}}\right)$. Briefly, one expects repeated snap-off of small bubbles in slitshaped throats $\left(\left(w_{\mathrm{t}} / d_{\mathrm{t}}\right) \rightarrow \infty\right)$, both at the gas-invasion front and behind the front (due to fluctuating capillary pressure). For throats of width comparable to aperture, snap-off depends on the geometry of the downstream body (its aperture and width). If the body is much deeper than the throat, or much wider than it is deep, snap-off is expected at the gas-invasion front, but resulting bubbles would be larger than for slit-shaped throats. Snap-off behind the front requires larger fluctuations in capillary pressure than for slit-shaped throats. If the body is not much deeper than the throat or much wider than it is deep, snap-off is not favored, but lamella division is.

Table 10 presents a characterization of the model fractures in terms of this analysis. The results agree on the whole with our observations. The snap-off of small bubbles is expected and observed in samples 2 and 4 (Figures 16 and 18). Conditions are somewhat less favorable for snap-off in sample 3 , and bubbles are larger (Figure 17), though these bubbles are reduced somewhat in size as they move downstream. Conditions are less favorable for snap-off in samples $4 \mathrm{a}$ and $4 \mathrm{~b}$ than in sample 4 , and indeed the bubble size increases from sample 4 to $4 \mathrm{a}$ to $4 \mathrm{~b}$ (Figure 19). Throat and body geometries are not favorable for snap-off in samples 1 and 5, and the primary mechanism for foam generation appears to be lamella division (Figures 15 and 20), though bubbles are reduced in size as they propagate in sample 5. Conditions are less favorable for snap-off in samples $5 \mathrm{a}$ and $5 \mathrm{~b}$ 
Table 10. Geometric Characterization of Model Fractures in Terms of Dimensionless Groups

\begin{tabular}{|c|c|c|c|c|c|}
\hline $\begin{array}{l}\text { sample } \\
\text { no. }\end{array}$ & $\begin{array}{l}\text { pore-throat } \\
\text { aperture, } d_{\mathrm{t}}\end{array}$ & $\begin{array}{l}\text { pore-body } \\
\text { aperture, } d_{\mathrm{b}}\end{array}$ & $\begin{array}{l}\text { pore-throat } \\
\text { width, } w_{\mathrm{t}}\end{array}$ & $\left(w_{t} / d_{t}\right)$ & $\begin{array}{l}\left(d_{\mathrm{b}} /\right. \\
\left.d_{\mathrm{t}}\right)\end{array}$ \\
\hline 1 & 818 & 1128 & 1550 & 1.89 & 1.37 \\
\hline 2 & 68 & 138 & 410 & 6.0 & 2 \\
\hline 3 & 443 & 853 & 1650 & 3.72 & 1.9 \\
\hline 4 & 100 & 210 & 1130 & 11.3 & 2.1 \\
\hline $4 a$ & 121 & 231 & 1130 & 9.33 & 1.91 \\
\hline $4 b$ & 253 & 363 & 1130 & 4.46 & 1.43 \\
\hline 5 & 131 & 211 & 460 & 3.51 & 1.61 \\
\hline $5 a$ & 161 & 241 & 460 & 2.86 & 1.50 \\
\hline $5 b$ & 186 & 265 & 460 & 2.47 & 1.43 \\
\hline
\end{tabular}

than in sample 5, and indeed the bubble size increases from sample 5 to 5 a to 5 b (Figure 21).

\section{SUMMARY AND CONCLUSIONS}

Experiments investigating foam generation, propagation, and mobility reduction were carried out using a variety of model fractures with different geometries. The following conclusions can be drawn:

1. Foam was generated in situ in different model fractures that varied in the magnitudes of the aperture, aperture variation within the fracture, and length scale over which the aperture varies. Foam in the model fractures was generated primarily by two processes: capillary snap-off and lamella division. In both cases the fracture-wall roughness played a major role in foam generation.

2. Two of the five fracture samples show only lamella division. This may reflect relatively wide apertures and a throat geometry less favorable for snap-off (i.e., less slitlike). The other three samples show both generation mechanisms at different foam qualities and superficial velocities.

3. In cases where foam is generated only by lamella division, gas enters the fracture and propagates for some distance as a continuous phase before additional films are created.

4. In all cases, bubbles smaller than the pores are generated and propagate through the fracture. The size of the bubbles is not always similar to the size of the pore, as is thought to be the case in $3 \mathrm{D}$ rock pore space, in part because bubbles reside for a time that is much shorter than the time required for diffusion to eliminate small bubbles. Moreover, snap-off can produce bubbles much smaller than pores in slit-shaped throats.

5. Very small pressure gradients were recorded for the samples with very large apertures. In these cases no foamquality scans could be conducted. In most cases, bubble size increased and pressure gradient declined as the aperture increased for the same roughness of the pore wall. In some cases, however, the mobility reduction factor increased relative to water; that is, as hydraulic aperture increased, the pressure gradient decreased less than the $(-3)$ power of the aperture (as it does for singlephase flow of water).

6. Foam-quality scans were carried out using three samples. The pressure-gradient data reveals, in two of the fractures, high- and low-quality flow regimes like those seen in rock matrix. However, the high-quality regime was controlled not by foam stability and coalescence but by fluctuations in foam generation, and bubble size was not fixed at pore size in the low-quality regime.

7. Hydraulic aperture alone is not enough to determine foam-generation behavior and mobility reduction. The roughness scale, both laterally and vertically, plays a significant role.

8. When the roughness scale was fixed, a significant reduction in pressure gradient was measured with increasing hydraulic aperture. Foam bubbles become larger as the aperture increases.

\section{ASSOCIATED CONTENT}

\section{Supporting Information}

The Supporting Information is available free of charge on the ACS Publications website at DOI: 10.1021/acs.energyfuels.8b02178.

Appendices A and B (PDF)

\section{AUTHOR INFORMATION}

\section{Corresponding Author}

*E-mail: bander.quaimi@gmail.com.

ORCID

B. I. AlQuaimi: 0000-0002-1967-9004

Notes

The authors declare no competing financial interest.

\section{ACKNOWLEDGMENTS}

The authors acknowledge Saudi Aramco for providing the scholarship for Mr. AlQuaimi, and also the generous support provided by the sponsors of the Joint Industry Project on Foam for Enhanced Oil Recovery at Delft University of Technology. Special thanks go to Sian Jones for her helpful comments and discussion.

\section{REFERENCES}

(1) Holm, L. Foam injection test in the Siggins field, Illinois. JPT, J. Pet. Technol. 1970, 22 (12), 1499-1506.

(2) Svorstøl, I., et al. Foam Pilot Evaluations for the Snorre Field, Part 2: Numerical Simulations and Economical Evaluations. IOR 1995-8th European Symposium on Improved Oil Recovery. Vierma, Austria, 1995.

(3) Svorstøl, I., et al. Foam Pilot Evaluations for the Snorre Field, Part 1: Project and Laboratory Results. IOR 1995-8th European Symposium on Improved Oil Recovery. Vierma, Austria, 1995.

(4) Blaker, T., et al. Foam for gas mobility control in the Snorre field: the FAWAG project. SPE Annual Technical Conference and Exhibition, Society of Petroleum Engineers, Houston, TX., 1999.

(5) Patzek, T. W. Field applications of steam foam for mobility improvement and profile control. SPE Reservoir Eng. 1996, 11 (02), $79-86$.

(6) Kam, S.; et al. Experimental study of high-temperature foam for acid diversion. J. Pet. Sci. Eng. 2007, 58 (1), 138-160.

(7) Nasr-El-Din, H. A., et al. Field Success in Carbonate Acid Diversion, Utilizing Laboratory Data Generated by Parallel Flow Testing. SPE Annual Technical Conference and Exhibition, USA Society of Petroleum Engineers, San Antonio, TX, 2006.

(8) Szafranski, R.; et al. Surfactant/foam process for improved efficiency of aquifer remediation. Structure, Dynamics and Properties of Disperse Colloidal Systems 1998, 111, 162-167.

(9) Nelson, R. Geologic analysis of naturally fractured reservoirs; Gulf Professional Publishing: 2001.

(10) Ozkaya, S. I. Detection of Fracture Corridors from Openhole Logs in Horizontal Wells. SPE Saudi Arabia Section Technical Symposium. 
SPE-110942-MS; Society of Petroleum Engineers: Dhahran, Saudi Arabia, 2007.

(11) Bertotti, G.; Immenhauser, A.; Koppen, J.K.J.T.-v. Stratigraphic and regional distribution of fractures in Barremian-Aptian carbonate rocks of Eastern Oman: outcrop data and their extrapolation to Interior Oman hydrocarbon reservoirs. Int. J. Earth Sci. 2005, 94 (3), 447-461.

(12) van Golf-Racht, T. D. Fundamentals of fractured reservoir engineering; Elsevier: 1982.

(13) Haugen, Å.; et al. Experimental study of foam flow in fractured oil-wet limestone for enhanced oil recovery. SPE Reservoir Evaluation \& Engineering 2012, 15 (02), 218-228.

(14) Haugen, Å.; et al. Miscible and immiscible foam injection for mobility control and EOR in fractured oil-wet carbonate rocks. Transp. Porous Media 2014, 104 (1), 109-131.

(15) Steinsbø, M., et al. Foam as mobility control for integrated CO2EOR in fractured carbonates. IOR 2015-18th European Symposium on Improved Oil Recovery. EAGE, Dresden, Germany, 14-16 April, 2015.

(16) Yan, W.; Miller, C. A.; Hirasaki, G. J. Foam sweep in fractures for enhanced oil recovery. Colloids Surf., A 2006, 282, 348-359.

(17) Buchgraber, M.; Castanier, L.M.; Kovscek, A. R. Microvisual investigation of foam flow in ideal fractures: role of fracture aperture and surface roughness. SPE Annual Technical Conference and Exhibition, Society of Petroleum Engineers, 2012.

(18) Gauteplass, J.; et al. Pore-level foam generation and flow for mobility control in fractured systems. Colloids Surf., A 2015, 468, 184192.

(19) Kovscek, A.; et al. Foam flow through a transparent rough-walled rock fracture. J. Pet. Sci. Eng. 1995, 13 (2), 75-86.

(20) Ferno, M. A.; et al. Experimental Study of Foam Generation, Sweep Efficiency, and Flow in a Fracture Network. SPE Journal 2016, 21 (4), 1140-1150.

(21) AlQuaimi, B. I.; Rossen, W.R. Study of foam generation and propagation in a fully characterized physical-model fracture. J. Pet. Sci. Eng., 2017. DOI: $10.1016 /$ j.petrol.2018.06.025

(22) Chen, C. Y.; Horne, R. N.; Fourar, M. Experimental study of liquid-gas flow structure effects on relative permeabilities in a fracture. Water Resour. Res. 2004, 40 (8), W08301.

(23) Chen, C. Y.; Li, K.; Horne, R.N. Experimental study of phase transformation effects on relative permeabilities in fractures SPE Annual Technical Conference and Exhibition, Society of Petroleum Engineers, 2004.

(24) Fourar, M.; Bories, S.; Lenormand, R. Experimental study of twophase flow in rough fractures. Proceedings, Seventeenth Workshop on Geothermal Reservoir Engineering; Stanford University: Stanford, CA, 1992: pp 215-218.

(25) Pieters, D.; Graves, R. Fracture relative permeability: linear or nonlinear function of saturation. International Petroleum Conference and Exhibition of Mexico, Society of Petroleum Engineers, 1994.

(26) Qian, J.; et al. Experimental study of the effect of roughness and Reynolds number on fluid flow in rough-walled single fractures: a check of local cubic law. Hydrological Processes 2011, 25 (4), 614-622.

(27) Pruess, K.; Tsang, Y. W. On two-phase relative permeability and capillary pressure of rough-walled rock fractures. Water Resour. Res. 1990, 26 (9), 1915-1926.

(28) AlQuaimi, B. I.; Rossen, W. R. Characterizing Foam Flow in Fractures for Enhanced Oil Recovery. 19th European Symposium on Improved Oil Recovery, Stavanger, Norway, 2017.

(29) AlQuaimi, B. I.; Rossen, W. R. New Capillary Number Definition for Displacement of Residual Nonwetting Phase in Natural Fractures. Geophys. Res. Lett. 2017, 44, 5368.

(30) Rossen, W.; Kumar, A.T. Single-and two-phase flow in natural fractures. SPE Annual Technical Conference and Exhibition. Society of Petroleum Engineers: Washington, D.C., USA, 1992.

(31) Tsang, Y. The effect of tortuosity on fluid flow through a single fracture. Water Resour. Res. 1984, 20 (9), 1209-1215.

(32) Hughes, R. G.; Blunt, M. J. Network modeling of multiphase flow in fractures. Adv. Water Resour. 2001, 24 (3-4), 409-421.

(33) Pyrak-Nolte, L. J.; Cook, N. G.; Nolte, D. D. Fluid percolation through single fractures. Geophys. Res. Lett. 1988, 15 (11), 1247-1250.
(34) AlQuaimi, B. I.; Rossen, W. R. Capillary desaturation curve additional figures. Delft University of Technology Repository: http:// dx.doi.org/10.4121/uuid:b959da2e-f955-4991-b2bc-b2514397671f, 2017.

(35) AlQuaimi, B. I.; Rossen, W. R. Capillary Desaturation Curve for Residual Nonwetting Phase in Natural Fractures. SPE J. 2017, 23, 0788.

(36) Rossen, W. R., Foams in enhanced oil recovery. Foams: Theory, Measurements and Applications; Prud'homme, R. K., Khan, S., Eds.; Marcel Dekker: New York, 1996; pp 413-464.

(37) Rossen, W. R. A critical review of Roof snap-off as a mechanism of steady-state foam generation in homogeneous porous media. Colloids Surf., A 2003, 225 (1), 1-24.

(38) Ransohoff, T.; Radke, C. Mechanisms of foam generation in glass-bead packs. SPE Reservoir Eng. 1988, 3 (02), 573-585.

(39) Khatib, Z.; Hirasaki, G.; Falls, A. Effects of capillary pressure on coalescence and phase mobilities in foams flowing through porous media. SPE Reservoir Eng. 1988, 3 (03), 919-926.

(40) Alvarez, J. M.; Rivas, H.J.; Rossen, W.R. Unified Model for Steady-State Foam Behavior at High and Low Foam Qualities. SPE J. 2001, 6, 325.

(41) Osterloh, W.; Jante, M. Effects of gas and liquid velocity on steady-state foam flow at high temperature. SPE/DOE Enhanced Oil Recovery Symposium; Society of Petroleum Engineers: 1992.

(42) Lenormand, R.; Zarcone, C.; Sarr, A. Mechanisms of the displacement of one fluid by another in a network of capillary ducts. $J$. Fluid Mech. 1983, 135, 337.

(43) Rossen, W. R.; Gauglitz, P. A. Percolation theory of creation and mobilization of foams in porous media. AIChE J. 1990, 36, 1176-1188.

(44) Rossen, W. R. Theory of mobilization pressure gradient of glowing goams in porous media. I. incompressible foam. J. Colloid Interface Sci. 1990, 136, 1-16.

(45) AlQuaimi, B. I. Investigation of foam generation, propagation and rheology in fractures. Ph.D. Dissertation, Delft University of Technology, 2017. 